\title{
SARS-CoV-2 Suppression and Early Closure of Bars and Restaurants : A Longitudinal Natural Experiment*
}

\author{
Reo Takaku ${ }^{\dagger}$ Izumi Yokoyama ${ }^{\ddagger}$ Takahiro Tabuchi ${ }^{\S}$ \\ Masaki Oguni ฯ Takeo Fujiwara ॥
}

August 7, 2021

\begin{abstract}
Despite severe economic damage, full-service restaurants and bars have been closed in hopes of suppressing the spread of SARS-CoV-2 worldwide. This study explores whether the early closure of restaurants and bars in February 2021 reduced symptoms of SARS-CoV-2 in Japan. Using a large-scale nationally representative longitudinal survey, we found that the early closure of restaurants and bars decreased the utilization rate among young persons (OR 0.688; CI95 $0.515 ? 0.918$ ) and those who visited these places before the pandemic (OR 0.754; CI95 0.594?0.957). However, symptoms such of SARS-CoV-2 did not decrease in these active and high-risk subpopulations. Among the more inactive and low-risk subpopulations, such as elderly persons, no discernible impacts are observed in both the utilization of restaurants and bars and the symptoms of SARS-CoV-2. These results suggest that the early closure of restaurants and bars without any other concurrent measures does not contribute to the suppression of SARS-CoV2 .
\end{abstract}

Keywords: SARS-CoV-2; Early closure of restaurants and bars; Difference in Differences

*This study was approved by the Institutional Review Board of the Osaka International Cancer Institute (No. 20084). This work was supported by the Japan Society for the Promotion of Science (JSPS) KAKENHI Grants (grant number 18H03062 and 21H04856, Dr.Takahiro Tabuchi, and 18K01632, Dr Aiura) and the Japan Agency for Medical Research and Development (AMED; grant number 2033648, Prof. Takeo Fujiwara).

$\dagger$ Associate Professor at the Graduate School of Economics, Hitotsubashi University. 2-1, Naka, Kunitachi, Tokyo 186-8601, Japan. Email: reo.takaku@r.hit-u.ac.jp Tel.: +81-42-580-8599.

${ }^{\ddagger}$ Associate Professor at the Graduate School of Economics, Hitotsubashi University. 2-1, Naka, Kunitachi, Tokyo 186-8601, Japan. Email: izumi.yokoyama@r.hit-u.ac.jp Tel.: +81-42-580-8598. Fax: +81-42-580-8598.

$\S$ Associate Director at the Cancer Control Center, Osaka Medical Center for Cancer and Cardiovascular Diseases, Osaka, Japan

"Graduate School of Economics, Hitotsubashi University. 2-1, Naka, Kunitachi, Tokyo 186-8601, Japan. Email: em205020@g.hit-u.ac.jp

"Professor at the Tokyo Medical and Dental University, School of Medicine, Japan. 


\section{Introduction}

During the fight against severe acute respiratory syndrome coronavirus 2 (SARS-CoV2), almost all developed countries shut down full service restaurants and bars, or implemented strong restrictions on their functioning(Madeira et al, 2021; Yang et al, 2020; Fairlie, 2020). During the third wave in the winter of 2020-2021, many countries also prohibited dining and drinking at restaurants, bars, and cafes, with only takeout or delivery services permitted. Even if they were allowed to be open, their operating hours were restricted. Because the restaurant industry occupies a large share of employment, these policies would increase the unemployment rate (Kong and Prinz, 2020) and firm exit (Miyakawa et al, 2021), and lead to the deterioration of the mental health of workers in this industry (Witteveen and Velthorst, 2020). In Japan, full service restaurants and bars will be under strict restrictions until August 31 2021, with the Tokyo Olympics being held during the same period.

Despite the significant economic damage, these policies were implemented in hopes of suppressing SARS-CoV-2 because plenty of scientific research suggest that full service restaurants and bars contributed to the spread of SARS-CoV-2 (Chang et al, 2020; Fisher et al, 2020; Brauner et al, 2021; Askitas et al, 2021; Haug et al, 2020; Persson et al, 2021). However, it is not clear whether this early evidence can be directly applied to the situation today for several reasons. First, these studies are based on data from the first wave when many other non-pharmaceutical interventions (NPIs) were jointly implemented (Brauner et al, 2021; Hale et al, 2021). Thus, it is quite difficult to separate the effects of closing restaurants and bars from the effects of other concurrent policies. In addition, during the first wave, many people in North American and European countries did not notice the importance of wearing masks (Howard et al, 2021; Kwon et al, 2021; Cheng et al, 2021) and washing their hands frequently (Makhni et al, 2021), which was proven to be effective in preventing SARS-CoV-2 afterwards. This situation is also quite different from that in the second or later waves, when most people voluntarily performed several preventive behaviors that were effective. Therefore, it is of particular importance to examine the effects of strict restrictions on restaurants and bars with much more timely data and better experimental settings.

In January and February 2021 Japan was exceptional, in that it could serve as an ideal experimental laboratory to investigate the effects of strong restrictions on restaurants and bars. During this period, there were no strict NPIs, except for the early closure of restaurants and bars. Neither city lockdowns, border restrictions, school closures, and stay-at-home orders with financial penalties were implemented. 


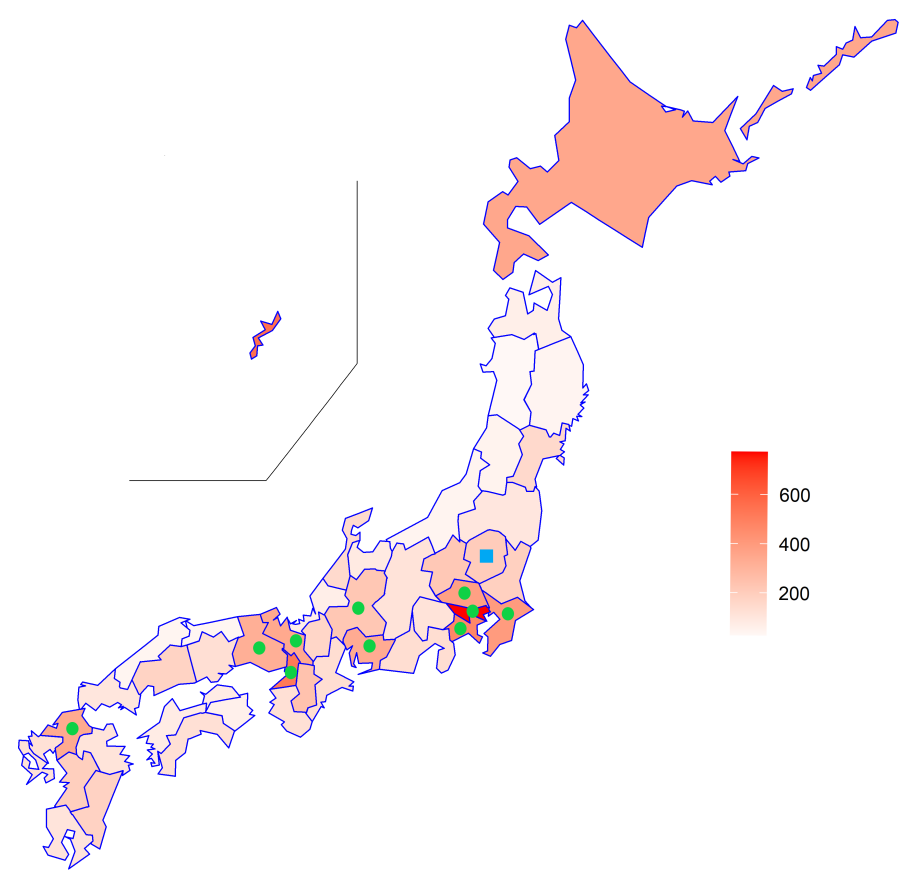

Figure 1: Infection Rate across Prefectures. The infection rate is per 100,000 persons. Note; Circles represent the 10 prefectures that declared SE in January and continued till the end of February. The square represents Tochigi prefecture, which declared the SE in January but lifted it on February 7 th.

This weak attitude toward the spread of SARS-CoV-2 is clearly different from that of other developed countries (Hale et al, 2021).

Instead, in Japan, 11 prefectures in Figure 1 declared a state of emergency (SE) in January and implemented strict restrictions on full service restaurants and bars. Specifically, 11 prefectural governments prohibited restaurants and bars to serve alcoholic beverages after 7 p.m., and forced them to close by 8 p.m., compensating for their financial loss with generous governmental subsidies. Among the 11 prefectures, the SE was lifted off only in the Tochigi Prefecture on February 7th, while other prefectures continued till the end of February. The local SE administration in Japan only asked the general population to stay at home voluntarily, without any explicit legal enforcement (Hosono, 2021; Watanabe and Yabu, 2021).

How does this policy of targeting restaurants and bars affect virus transmission? The answer hinges on how the people affected by this policy, namely those who frequently visited restaurants and bars, changed their behavior. One scenario is that they had to stay at home and not go anywhere at night. In this scenario, this targeting 
policy effectively suppress SARS-CoV-2 transmission. However, this is an optimistic view of the effectiveness of the policy. In reality, the people who were affected by this policy were not scared of SARS-CoV-2 generally, and behaved carelessly spreading the infection. For example, since many people celebrate the new year with relatives and friends in January, it is possible that the new year parties changed their venues rather than being canceled. In this case, the effectiveness of SARS-CoV-2 suppression would be quite limited.

In addition, it should be noted that, unlike the first wave, many individuals started with a much higher awareness of preventive behaviors in the third wave. Thus, it should be re-examined whether the early closure of restaurants and bars, in addition to a high standard of preventive behavior, reduced the spread of SARS-CoV-2 at the same level as predicted in the first wave. Consistent with this view, evidence from the UK found that early closure of restaurants and bars in September 2020 had no measurable effect on contacts (Jarvis et al, 2021), because the level of contacts was already quite low after the first wave. Even in the evidence from the first wave, some studies find that the effects of closing restaurants and bars are limited when other strict measures are implemented (Post et al, 2021).

Most importantly, previous studies consistently pointed out that people reduced their mobility mainly because of the fear of SARS-CoV-2, rather than governmental interventions such as shelter-in-place orders (Goolsbee and Syverson, 2021; Berry et al, 2021; Sheridan et al, 2020). Therefore, policies targeting restaurants and bars would have a very small impact on overall mobility and contacts, without a strong fear of SARS-CoV-2 itself.

To investigate the impacts of this policy, we estimated the difference in subjective symptoms of SARS-CoV-2 (Struyf and Van den Bruel, 2021; Miyawaki et al, 2021) between individuals under the Japanese SE declaration and others. Given that many studies suggest that the fear of SARS-CoV-2, not policies, induced voluntary reduction of mobility (Goolsbee and Syverson, 2021; Yan et al, 2021), a naive comparison between persons within prefectures with SE declaration and those without may contaminate the effects of the policy with the direct effects of fear itself. In fact, the early closure of restaurants and bars was implemented because of the spread of SARS-CoV-2; thus, it is still challenging to separate the effects of the policy from the direct effects of the virus, even if no other strict policies were implemented.

To overcome this challenge, we focus on individuals who live close to the borders of the prefectures with SE declaration and those without, by using the zip-code of respondents, in the same spirit as the geographical regression discontinuity analysis 
medRxiv preprint doi: https://doi.org/10.1101/2021.08.07.21261741; this version posted August 8, 2021. The copyright holder for this preprint (which was not certified by peer review) is the author/funder, who has granted medRxiv a license to display the preprint in perpetuity.

All rights reserved. No reuse allowed without permission.

(Dell, 2010; Dell et al, 2018). This empirical strategy seems to be useful because the fear of infection would be sufficiently similar in geographically close areas. Another feature of our methodology is that we use nationally representative longitudinal data with a short interval of only four months. Because the interval between the first and second waves is only four months, we could successfully absorb individual-level unobservables by incorporating individual fixed effects. With this research design, we study the effects of the early closure of full service restaurants and bars on (a) the utilization of full service restaurants (Japanese pubs) and bars in the past one month, and (b) 5 symptoms indicative of SARS-CoV-2, which are validated in previous studies (Struyf et al, 2020; Sonoda et al, 2021; Miyawaki et al, 2021).

\section{Data and Research Design}

\section{$2.1 \quad$ Data}

We study the effects of closing restaurants and bars by using a nationally representative internet survey, named the Japan COVID-19 and Society Internet Survey (JACSIS) (Zaitsu et al, 2021; Miyawaki et al, 2021). This web-based, self-reported questionnaire survey was administered by a large internet research agency Rakuten Insight, Inc.. The questionnaires were distributed to 224,389 individuals aged between 15-79 years old, and 28,000 responded during the first wave. The participants had the option of not responding to any part of the survey questionnaire, and discontinuing the survey at any point. The response rate was $12.5 \%$. The surveys for the first and second waves were conducted in August and September 2020 and February 2021, respectively. Note that the second survey was conducted when the SE was declared in 10 prefectures, except Tochigi which declared the SE in January but lifted it in early February. From the dataset in the first wave, we chose 25,691 individuals, after excluding those with missing values. A total of 4,775 individuals were dropped in the second wave. The follow-up rate was $81 \%$. Finally, we constructed a balanced panel data of 20,916 persons. The descriptive statistics are shown in SI Appendix Table S1.

\subsection{Main Outcomes}

Our key dependent variable was the utilization of restaurants and bars within the past month. Specifically, restaurants and bars include Izakaya pubs, a common type of Japanese pubs that serve alcoholic beverages and a variety of tidbits. For simplicity, they will be referred to as "Japanese pubs" hereafter. Because the SE declaration in 
January and February 2021 explicitly prohibited these Japanese pubs and bars from serving alcoholic beverages after 7 p.m., and ordered them to be closed by 8 p.m., we expected the utilization rate to decrease. The 7 p.m. curfew for serving alcoholic beverages is crucial to the management of Japanese pubs, because Japanese people generally start drinking parties around 7 p.m. Therefore, curfews are regarded as a substantial business suspension order for Japanese pubs. In fact, a popular chain of Japanese pubs, Watami, completely shut down half their outlets.

On the health outcomes, we use 5 subjective symptoms indicative of SARS-CoV2 (high fever, sore throat, cough, headache, and smell and taste disorder). Because there were a limited number of PCR tests in Japan, self-reported SARS-CoV-2 like symptoms have been regarded as a useful measure to detect persons with SARS-CoV2 (Struyf et al, 2020; Nomura et al, 2020; Menni et al, 2020; Miyawaki et al, 2021). In addition, the validity of these symptoms has been confirmed in the environment in Japan (Sonoda et al, 2021). For example, for fever, the sensitivity was at least $80 \%$ in many studies, and the specificity was more than $90 \%$. The specificity was also high for cough (at least 50\%), sore throat (70\%), headache (80\%), and smell and taste disorder (90\%) (Struyf et al, 2020; Sonoda et al, 2021; Miyawaki et al, 2021).

We explore how the early closure of Japanese pubs and bars affects these dependent variables by comparing people who lived in the 10 prefectures with SE declarations (treatment group) and others (control group). In the first step, we implement a difference-in-differences analysis by controlling for individual-level time-varying covariates, such as income levels and smoking behaviors. Then, we focus on the persons who live in areas close to the borders of the 10 prefectures because the fear of SARSCoV-2 was supposed to be similar between the treatment and control groups. The residence of an individual is identified by calculating the centroid of the zip code of the respondents. In the most preferred specification, we additionally exclude individuals who lived in areas too close to the border, because they can easily cross the border and go to Japanese pubs and bars located in neighboring prefectures which had no restrictions.

\subsection{Research Design and Empirical Model}

The intuition for this analysis is shown in Figure 2. In this figure, we plot the utilization rate of Japanese pubs and bars during the first and second waves, around the border of the 10 prefectures. On the horizontal axis, the negative (positive) sign represents the area without (with) the SE declaration. Because the SE was declared in urban 


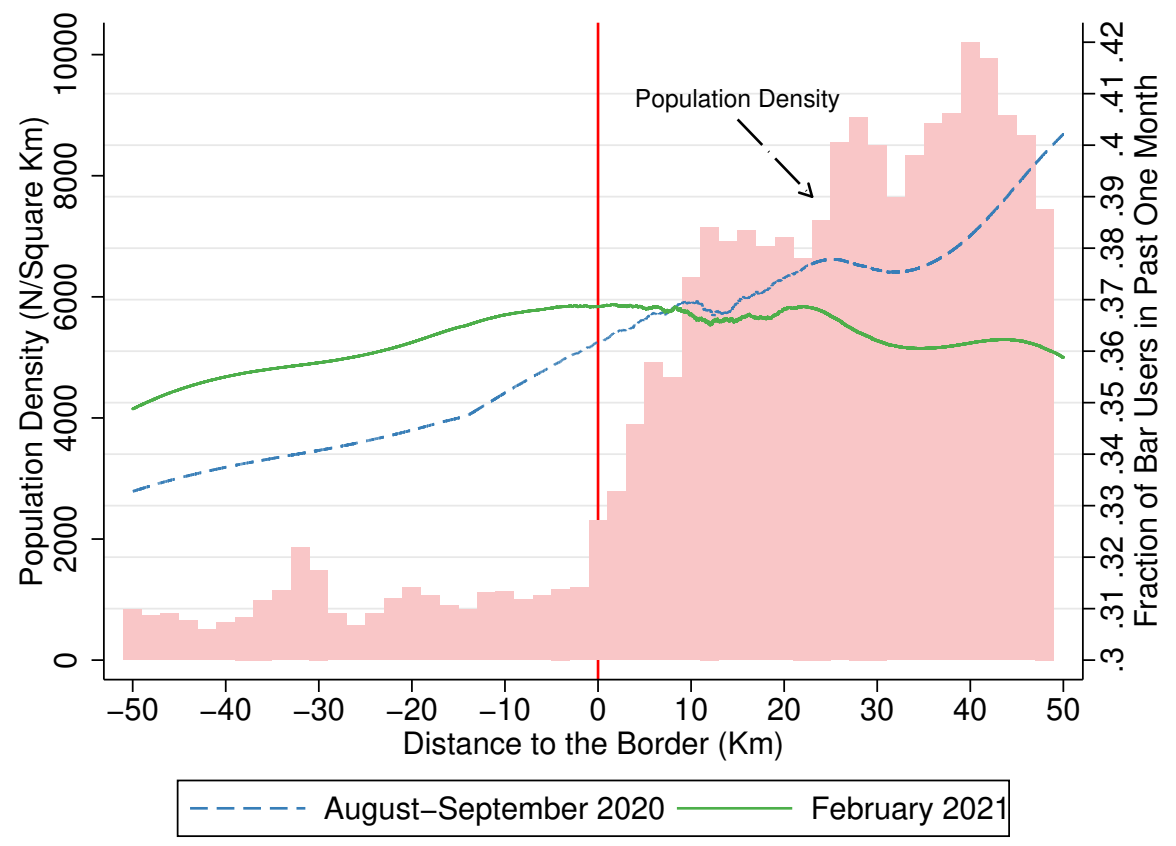

Figure 2: Population Density and Utilization of Japanese Pubs around the Border

Note; The fraction of persons who went the Japanese pubs and bars are represented in lines which are derived from local polynomial fit. The vertical line represents the border that splits prefectures with (positive sign) and without (negative sign) the state of emergency declaration. 
areas, population density, which is shown in the histogram, increases as the distance to the border moves from $-50 \mathrm{~km}$ to $50 \mathrm{~km}$. Reflecting an increase in urbanity, the utilization rate of Japanese pubs and bars exhibits an upward slope from August to September 2020. Note that the utilization rate is about $36 \%$ at the border from August to September 2020 and in February 2021, suggesting that the use of Japanese pubs is common in Japanese society. In addition, the utilization rate in February, when the SE was declared, followed a parallel trend with that in August-September 2020, in the area outside the 10 prefectures. However, in the area inside the 10 prefectures, the utilization of Japanese pubs and bars drops to a larger extent, when compared to the trend in August -September 2020.

In the actual implementation, we use a fixed-effect linear probability model as well as a random effect logistic regression model. In the fixed-effect linear probability model, the estimated equation is as follows:.

$$
y_{i t}=\beta_{0} \text { Treat }+\mathbf{X}_{\mathbf{i t}} \gamma+\theta_{i}+\beta_{1} \text { Wave }_{2}+\epsilon_{i t},
$$

where $y_{i t}$ is a dependent variable for individual $i$ in wave $t$ : Treat is a binary variable that takes a value of 1 if the individual $i$ lived in prefectures with a state of emergency declaration during the second wave, mainly in February 2021: $X_{i t}$ is a vector of time-varying covariates, $\theta_{i}$ is an individual fixed effect: $W a v e_{2}$ is a binary variable for wave 2 , and $\epsilon_{i t}$ is an idiosyncratic error term.

In this equation, we control for age, working status (i.e., job loss or not), marital status, smoking, and household income level. The household income level is measured by a binary variable that takes a value of 1 for households with an annual income of JPY 7 million (USD 70,000) or more. In the random effect logistic regression model, we additionally controlled for educational qualification and the prefecture where individual $i$ lived in each wave. Standard errors are clustered at the prefecture level in the fixedeffect linear probability model.

\subsection{Definition of the Groups in Subsample Analysis}

In the subsample analysis, we generated eight subgroups. The "young persons" represents the individuals who are less than 40 years old and elderly persons refers to those above. In addition, we split the sample by educational qualification(i.e., college graduate vs. non-college graduate). The number of "young persons" and "college graduate" in our data were 6,004 (29.1\%) and 10,566 (51.38\%), respectively.

Next, we split the sample based on the question about the frequency of utilization 
of Japanese pubs and bars before the pandemic, which was asked in the first survey. Specifically, the survey asked the question, "How many time did you go to Japanese pubs and bars before the pandemic ?" We created a binary variable that takes a value of one if the respondent answered "more than once a month" and called them "Regular users". The number of "Regular users" was 8,641 (41.9\%) in our data.

Finally, we also asked about fear of SARS-CoV-2 ("Are you scared of SARS-CoV-2 ?"). The answer is chosen from a 5 point Likert scale, namely "Very scared (1)," "Scared (2)," "Neither(3)," "Not scared(4)," and "Not scared at all(5)." From these answers, we categorized individuals who chose 3 to 5 as one group and the others as another group. The number of individuals in the former group (i.e., those who were not scared of SARS-CoV-2) was 7,438 (36.1\%).

\section{Results}

\subsection{Utilization of full service restaurants (Japanese pubs) and bars}

We estimate the differences in the utilization of Japanese pubs and bars among persons who were differently exposed to the restrictive policy by using the fixed-effect linear probability model and random effect logistic regression model in 1. In Column 1, we find a statistically significant reduction in the utilization rate (OR 0.896; CI95 0.814 - 0.966), even without any individual-level covariates and naive specifications, which compares the persons in the prefectures with and without the SE declaration.

This result is robust when we additionally control for individual-level time-varying covariates in Column (2) and focus on the persons who live in within $50 \mathrm{~km}$ from the border, which separates prefectures with and without SE declarations in Column (3).

While the specification in Column (3) is robust for confounders such as direct behavioral effects from the virus itself (i.e., fear of the infection), we severely underestimate their impacts in Column (3) because people under SE declaration can easily migrate to nearby prefectures when they wished, to visit Japanese pubs and bars.

To avoid a potential underestimation of the impact, we excluded people who lived within 10 to $20 \mathrm{~km}$ from the border in Columns (4) and (5), respectively. These results are consistent with our predictions. The estimated odds ratio (OR) for people who lived in prefectures with the SE declaration was 0.820 (CI95 0.700-0.960) in Column (4). The effect in terms of odds ratio is much higher in Column (5) (OR 0.771; CI95 0.640-0.930]. 


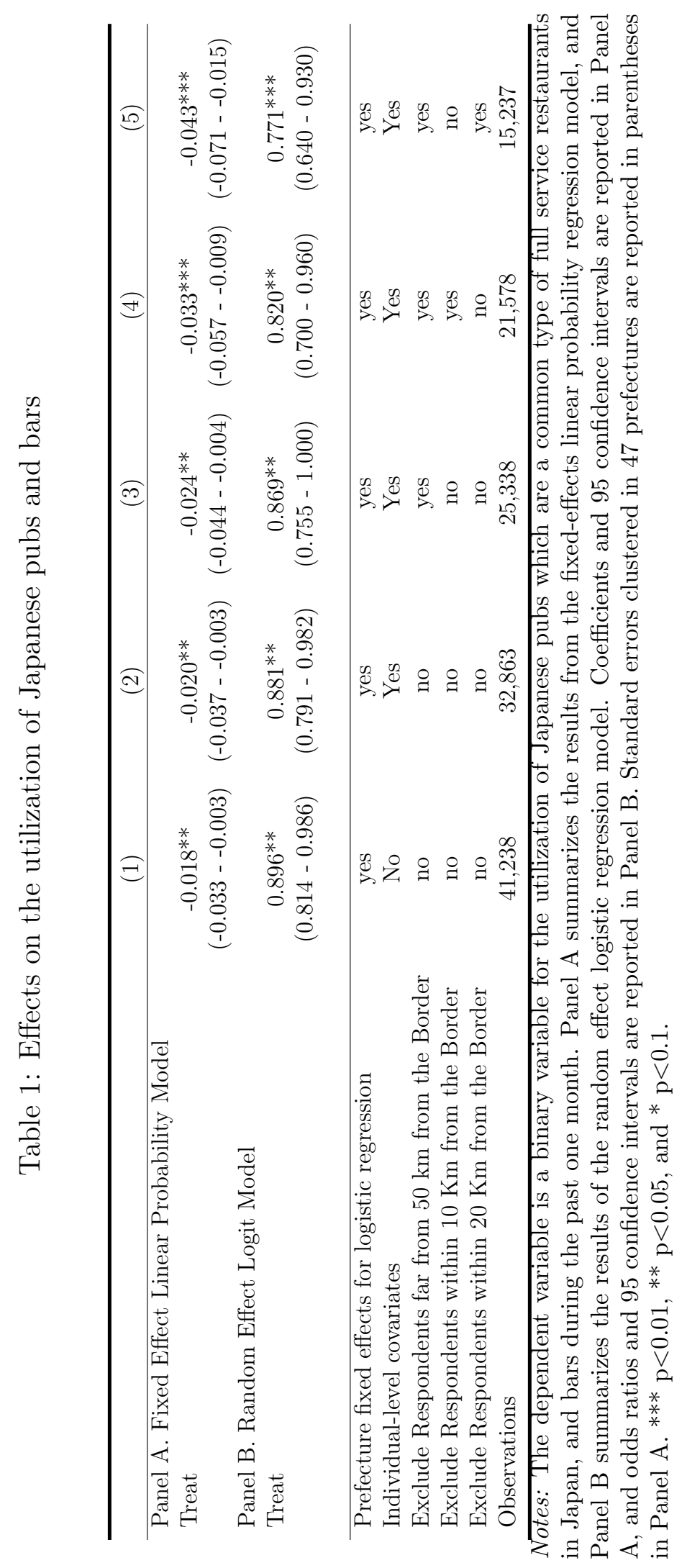


We move to the subsample analysis next because the early closure of Japanese pubs and bars has nothing to do with those who do not use them frequently. In fact, in SI Appendix Figure SI1, we find that the utilization rate of restaurants and bars was 48 $\%$ among people who were not scared of SARS-CoV-2 at all, but $30 \%$ among those who were very scared in August-September 2020, when no restrictive measures were implemented.

With this in mind, we implemented a subsample analysis according to age, educational qualification, use of Japanese pubs and bars before the pandemic, and how scared of SARS-CoV-2. The results are presented in Figure 3. In this figure, the odds ratio and 95 percent confidence intervals from the three specifications used in Columns (3) to (5) in Table 1 are plotted. The full tables for the results in Figure 3 are shown in SI Appendix Tables S2-S9.

From Figure 3, we find that the utilization of Japanese pubs and bars reduced among young persons and regular users, while there are no statistically significant decreases among elderly persons and non-users. Among young people, the odds ratio was 0.688 (CI95: 0.515-0.918) in our preferred specification, which excludes an area within $10 \mathrm{~km}$ from the border. In terms of percentage point changes derived from the fixed-effect linear probability model in SI Appendix Table S2, it is equivalent to a $7.2 \%$ point reduction in the utilization rate (CI95: -12.2pp - -2.2pp).

Regarding educational attainment, we found a much larger reduction in the use among college graduates than among non-college graduates. Regarding fear of SARS$\mathrm{CoV}-2$, we found that the ORs were lower among people who were not scared of the virus than among those who were scared. In terms of percentage point changes, the utilization rate among persons who was not scared of SARS-CoV-2 decreased by $4.7 \%$ points (CI95: -9.3pp - -0.1pp) in SI Appendix Table S8.

\subsection{Symptoms indicative of SARS-CoV-2}

Given that the early closure of Japanese pubs and bars significantly reduces their use among some high-risk subpopulations, such as young people, and the users of these services, this may lead to the reduction of symptoms related to SARS-CoV-2 mainly among these groups.

According to the descriptive statistics for five symptoms (fever, sore throat, cough, headache, and smell and taste disorder) in the SI Appendix Table S1, the proportion of people with each symptom was $1.8 \%$ (fever), $11.4 \%$ (sore thraot), $13.1 \%$ (cough), headache $(1.9 \%)$, and $1.2 \%$ (smell and taste disorder). We also found that smell and 


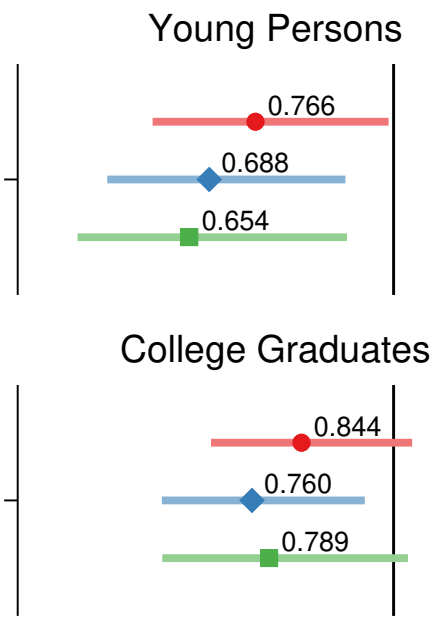

Regular Users

$$
1
$$

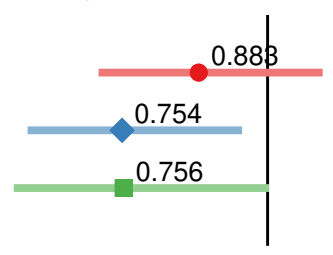

Scared

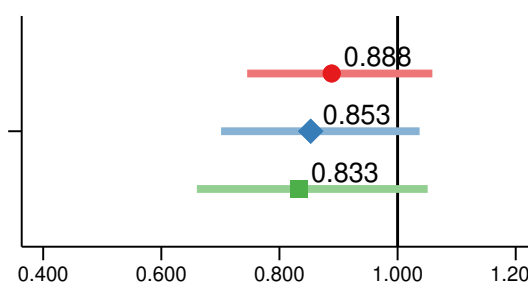

Odds Ratio \& $95 \%$ Cls
Elderly Persons

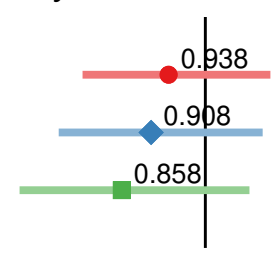

Non College Graduates

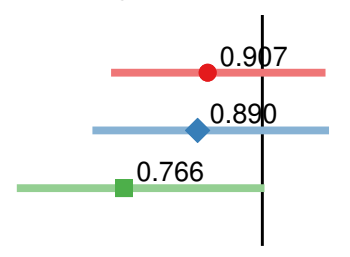

Non Regular Users

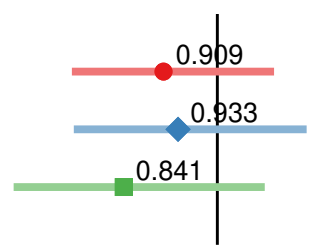

Not Scared

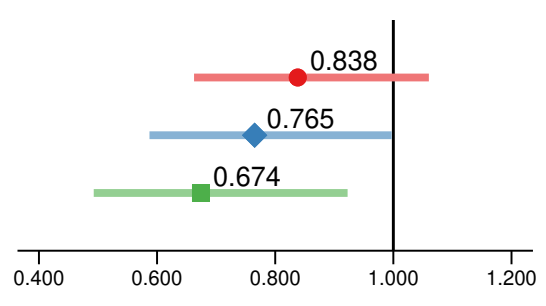

\section{Baseline Exclude $10 \mathrm{Km}$ - Exclude $20 \mathrm{Km}$}

Figure 3: Effects on the utilization of Japanese pubs and bars by individual characteristics.

Notes: Odds ratios (ORs) and 95 percent confidence intervals (CIs) were calculated using a random effect logistic regression model. The baseline specification controls for individual-level covariates as well as prefecture fixed effects, and excludes people who live in areas more than $50 \mathrm{~km}$ from the border of the prefectures with SE declarations. This specification is also used in Column (3) of Table 1. The "young persons" represents those aged less than 40 years old. "Regular users" represents the individuals who used Japanese pubs, which are a common type of full service restaurant in Japan, and bars before the pandemic. 
taste disorder, which has the highest specificity for the infection of SARS-CoV-2 among these five symptoms, increased from $0.8 \%$ in August-September 2020, to 1.3\% in February 2021.

The results of the full sample for the five symptoms are listed in Table 2. The specifications in Columns (1) to (5) are the same as those in Table 1. In this table, we do not find any statistically significant reductions at the $95 \%$ significance level for all the symptoms. In our preferred specifications in Column (4), the odds ratio for fever exceeds 1, strongly rejecting the reduction (OR 1.222; CI95 0.697-2.141]. The odds ratios for headache, smell, and taste disorder were 0.966[CI95 0.493-1.894] and 0.808 (CI95 0.362-1.807), respectively. 


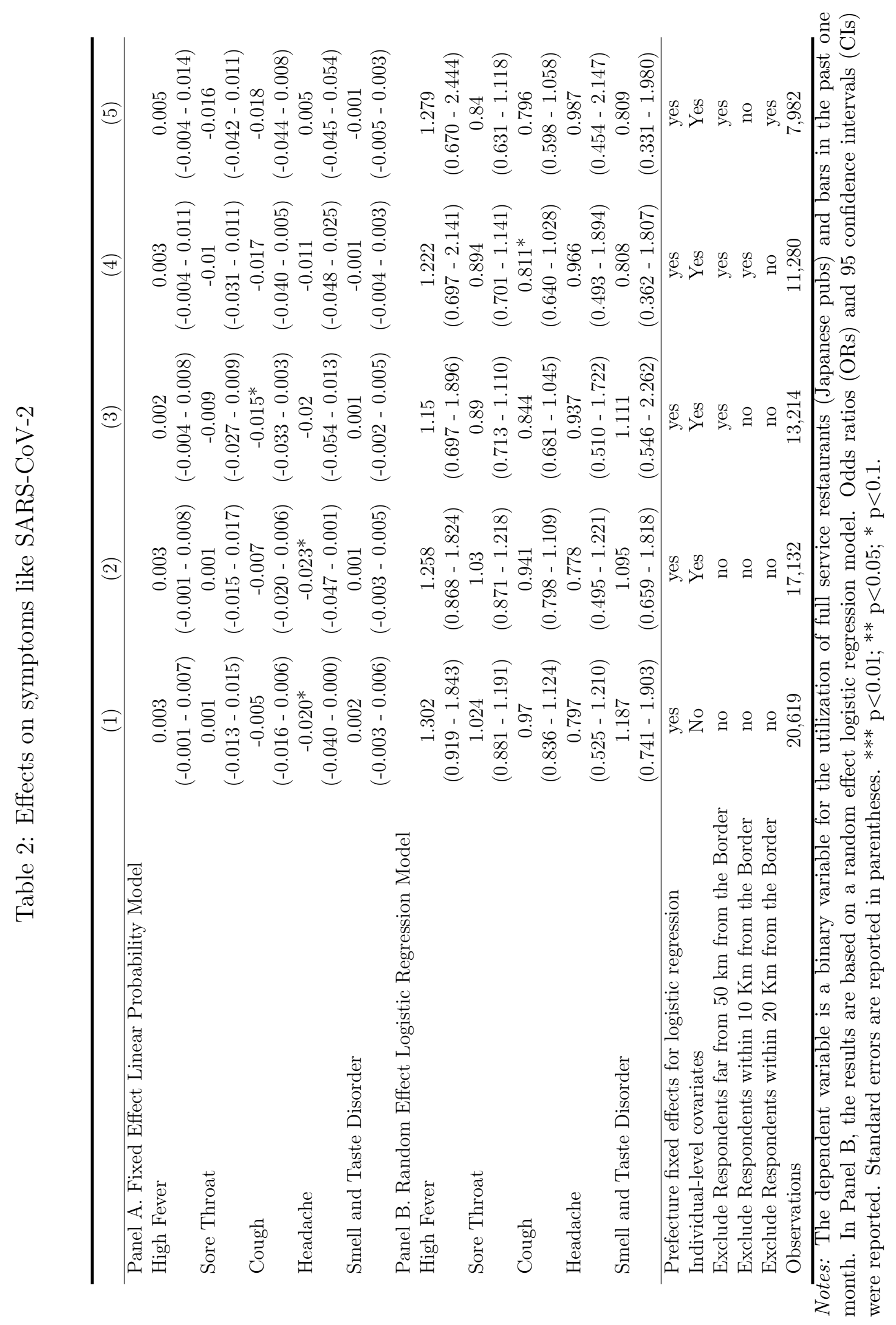


medRxiv preprint doi: https://doi.org/10.1101/2021.08.07.21261741; this version posted August 8, 2021. The copyright holder for this preprint (which was not certified by peer review) is the author/funder, who has granted medRxiv a license to display the preprint in perpetuity.

All rights reserved. No reuse allowed without permission.

Figure 4 summarizes the results of the subsample analysis. Although we find large reductions in the utilization of Japanese pubs and bars among young people, regular users, and those who were not scared at SARS-CoV-2, the odds ratio for fever among young persons is 0.960 [CI95 $0.431-2.134$ ], suggesting no statistically significant reduction. On smell and taste disorder, we find odds ratios are rather positive among young persons, regular users, and those who were not scared at SARS-CoV-2. Only among college graduates do we find a statistically significant reduction of cough (OR 0.651; CI95 0.465 - 0.911).

We found no statistically significant effects for the outcomes among other subpopulations. Among elderly persons who were not strongly affected by the strict measures for Japanese pubs and bars, all odds ratios were not statistically significant, as expected.

The results from the fixed-effect linear probability model in SI Appendix Tables S10S17 is totally consistent with those from the random effect logistic regression model.

\section{Discussion}

In this paper, we explore how the early closure of full-service restaurants (Japanese pubs) and bars in Japan during the third wave of the SARS-CoV-2 pandemic affected the utilization of these services and the incidence of symptoms indicative of SARS-CoV2. During the third wave, 10 prefectures declared an SE in January and prohibited restaurants and bars to serve alcoholic beverages after 7 p.m. and forced them to close by 8 p.m. Unlike other countries experiencing the first wave, no other strict measures such as school closures and border restrictions were implemented in Japan. Therefore, Japan during the winter 2020-2021 can be regarded as an ideal laboratory to explore the effects of the early closure of restaurants and bars.

By using large-scale nationally representative survey data and focusing on the people who live sufficiently close to the border that separates prefectures with and without SE declarations, we find a large reduction in the utilization of Japanese Izakaya pubs, which are a common type of full-service restaurants in Japan, and bars. In particular, the impacts are large among young people(OR 0.688; CI95 0.515 - 0.918) and regular users of these services (OR 0.754; CI95 0.594 - 0.957). Despite the reduction of the utilization rate, we find no discernible decrease in the symptoms of SARS-CoV-2, except the reduction of "cough" among college graduates. In the inactive and low-risk subpopulations (e.g., elderly persons), as expected, no changes were observed in both the utilization and the symptoms found. 

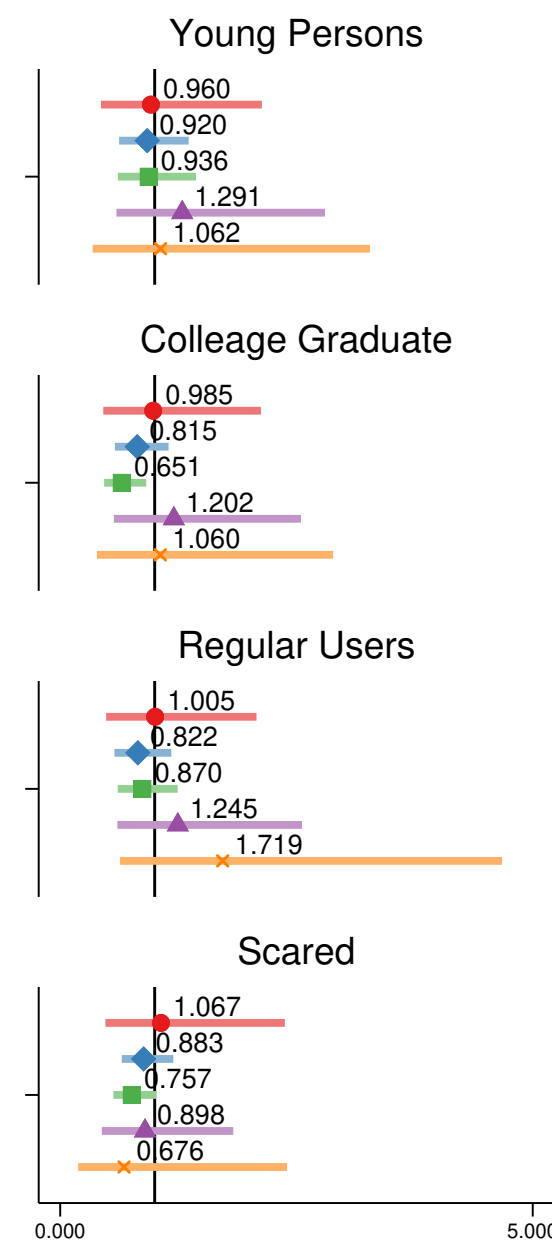

Odds Ratio \& $95 \%$ Cls

\begin{tabular}{|ll|}
\hline- High Fever & Sore Throat \\
$\square$ Cough & $\Delta$ Headache \\
$\times$ Smell and Taste & \\
\hline
\end{tabular}

Figure 4: Effects on Symptoms of COVID-19

Notes: Odds ratios (ORs) and 95 percent confidence intervals (CIs) were calculated using the random effect logistic regression model. The specification is the same as that in Column (4) of Table 2. "Young persons" represents those less than 40 years old. "Regular users" represents individuals who regularly used Japanese pubs, which are a common type of full service restaurant in Japan, and bars before the pandemic. 
The results from our analysis exhibit a sharp contrast to the existing evidence that supports the effectiveness of the early closure of full-service restaurants and bars in restraining the spread of SARS-CoV-2 (Chang et al, 2020; Fisher et al, 2020; Brauner et al, 2021; Askitas et al, 2021; Haug et al, 2020; Persson et al, 2021). There are several reasons why our study did not find any discernible impact of the early closure policies. First, we should examine whether full-service restaurants and bars contribute to the spread of SARS-CoV-2, and if it could be linked to the standard of daily preventive behavior. In the second and third waves, most people knew the importance of wearing masks and washing hands frequently. In particular, compliance with these preventive behaviors was quite high in Japan because of its collectivist culture (Lu et al, 2021), which is different from that in the US (Bazzi et al, 2021). Thus, it is possible that the additional effects of early closure, though not completely null, are limited. At least, the effects of suppressing SARS-CoV-2, which were predicted based on the evidence from the first wave (Chang et al, 2020; Fisher et al, 2020; Brauner et al, 2021; Askitas et al, 2021; Haug et al, 2020; Persson et al, 2021) would be a substantial overestimation of the actual effects during the later waves. Therefore, more research is needed to investigate the effects of the early closure changes over time.

Second, early closure affects only high risk subpopulations, who may be prone to other risky behaviors. Thus, it is possible that they will eventually become infected, even if full-service restaurants and bars are closed. To support this interpretation, we additionally explore the effects on daily going-out behaviors such as "avoid crowds", "not go traveling," "maintaining social distance," and "avoiding non-essential outings" in SI Appendix Figures S2. In short, we find no discernible impacts on these outcomes, suggesting that, even without going to full-service restaurants and bars, the overall tendency to go out remained almost unchanged among high-risk subpopulations. This is consistent with evidence from the UK that the early closure of full-service restaurants and bars in September 2020 did not reduce contact (Jarvis et al, 2021).

Note that our results do not seem to be compatible with some evidence that government subsidies aimed at encouraging people to eat out in restaurants such as the UK's Eat-Out-to-Help-Out scheme spread SARS-CoV-2 (Fetzer et al, 2020). One study in Japan also found that the Japanese version of this government subsidy increased the symptoms of SARS-CoV-2 (Miyawaki et al, 2021). However, it is natural to think that subsidization and early closure may have asymmetric impacts on the spread of SARSCoV-2. Specifically, the subsidization to eat out in restaurants largely increased the number of people coming into contact with each other, but the early closure may have limited impacts on such contacts because people meet and chat with their friends and 
colleagues in other places (Jarvis et al, 2021). Therefore, our results are still compatible with earlier studies on the effects of subsidies (Fetzer et al, 2020; Miyawaki et al, 2021).

Although this study is the first to investigate the independent effects of the early closure of restaurants and bars, there are several limitations. First, in our experimental setting, individuals in the prefectures with SE declarations could migrate to nearby prefectures to eat in restaurants and drink at bars. Thus, it is still possible that a nationwide closure, not local closures, would suppress the spread of SARS-CoV-2. However, in the preferred specification used in Figure 4, individuals living in an area within $10 \mathrm{~km}$ from the border to separate prefectures with and without SE declarations were excluded because they can easily cross the border; thus, our results are sufficiently robust to potential migration, and implications from our paper would be still applicable for the effects of a nationwide closure.

The second limitation is related to the stable unit treatment value assumption (SUTVA) (Rubin, 2005; Halloran and Struchiner, 1995; VanderWeele, 2008). Because infectious diseases spread locally and rapidly, neighboring areas generally tend to have similar infection rates. Therefore, our research may underestimate the impact of the policy, even if the early closure of restaurants and bars suppresses SARS-CoV-2 to a large extend. However, if this threat is relevant, we should have found large negative effects in the models that include persons far from the border, like in Columns (1) and (2) in Table 2, because the spillover effects from the prefectures with SE declarations to those without may not reach areas far away from the border. However, the odds ratios from these specifications regarding fever, sore throat, cough, and smell and taste disorder are generally higher than the odds ratios in Columns (3) to (4). This pattern of results is not compatible with the instantaneous spread of SARS-CoV-2 within local areas. Previous studies have also shown that SARS-CoV-2 spreads through commuting (Kissler et al, 2020) and traveling (Chinazzi et al, 2020), which are not always limited to areas that are geographically close to each other.

From the perspective of public policy implications, our study suggests that the early closure of full-service restaurants and bars, without any other concurrent policies, is not an efficient way to suppress SARS-CoV-2. Given the large detrimental effects on employment (Kong and Prinz, 2020; Miyakawa et al, 2021), alternative measures for full-service restaurants and bars should be considered before they are closed completely. For example, a combination of much more moderate NPIs, such as bans on small gatherings (Persson et al, 2021) and early detection and isolation (Lai et al, 2020) would perform better than only targeting full-service restaurants and bars. Evidence 
medRxiv preprint doi: https://doi.org/10.1101/2021.08.07.21261741; this version posted August 8, 2021. The copyright holder for this preprint (which was not certified by peer review) is the author/funder, who has granted medRxiv a license to display the preprint in perpetuity.

All rights reserved. No reuse allowed without permission.

also suggests that the effectiveness of NPIs largely depend on the combination of the interventions implemented (Nishi et al, 2020; Haug et al, 2020; Brauner et al, 2021). In addition, in an effective combination with other NPIs, the early closure policy can be replaced by weaker measures, such as a limitation on the number of seats served per table. Such moderate interventions would be, if implemented successfully, far more efficient to make the infection control compatible with the freedom of business among full-service restaurants and bars. Currently, Japanese pubs and bars in Tokyo are still subject to an early closure policy in order to curb the potential spread of SARS-CoV-2 during the Tokyo Olympics. Many Japanese people also doubt the legitimacy of the early closure policy during the Tokyo Olympics; thus, after the Tokyo Olympics will be over, alternative measures for full-service restaurants and bars should be implemented rapidly.

\section{References}

Askitas N, Tatsiramos K, Verheyden B (2021) Estimating worldwide effects of nonpharmaceutical interventions on covid-19 incidence and population mobility patterns using a multiple-event study. Scientific reports 11(1):1-13

Bazzi S, Fiszbein M, Gebresilasse M (2021) "rugged individualism" and collective (in) action during the covid-19 pandemic. Journal of Public Economics 195:104,357

Berry CR, Fowler A, Glazer T, Handel-Meyer S, MacMillen A (2021) Evaluating the effects of shelter-in-place policies during the covid-19 pandemic. Proceedings of the National Academy of Sciences 118(15)

Brauner JM, Mindermann S, Sharma M, Johnston D, Salvatier J, Gavenčiak T, Stephenson AB, Leech G, Altman G, Mikulik V, et al (2021) Inferring the effectiveness of government interventions against covid-19. Science 371(6531)

Chang S, Pierson E, Koh PW, Gerardin J, Redbird B, Grusky D, Leskovec J (2020) Mobility network models of covid-19 explain inequities and inform reopening. Nature pp 1-6

Cheng Y, Ma N, Witt C, Rapp S, Wild PS, Andreae MO, Pöschl U, $\mathrm{Su} H$ (2021) Face masks effectively limit the probability of sars-cov2 transmission. Science 372(6549):1439-1443, DOI 10.1126/science.abg6296, URL https://science.sciencemag.org/content/372/6549/1439, https:// science.sciencemag.org/content/372/6549/1439.full.pdf

Chinazzi M, Davis JT, Ajelli M, Gioannini C, Litvinova M, Merler S, Pastore y Piontti A, Mu K, Rossi L, Sun K, Viboud C, Xiong X, Yu H, Halloran ME, Longini IM, 
medRxiv preprint doi: https://doi.org/10.1101/2021.08.07.21261741; this version posted August 8, 2021. The copyright holder for this preprint (which was not certified by peer review) is the author/funder, who has granted medRxiv a license to display the preprint in perpetuity.

All rights reserved. No reuse allowed without permission.

Vespignani A (2020) The effect of travel restrictions on the spread of the 2019 novel coronavirus (covid-19) outbreak. Science 368(6489):395-400, DOI 10.1126/ science.aba9757, URL https://science.sciencemag.org/content/368/6489/ 395, https://science.sciencemag.org/content/368/6489/395.full.pdf

Dell M (2010) The persistent effects of peru's mining mita. Econometrica 78(6):18631903

Dell M, Lane N, Querubin P (2018) The historical state, local collective action, and economic development in vietnam. Econometrica 86(6):2083-2121

Fairlie R (2020) The impact of covid-19 on small business owners: Evidence from the first three months after widespread social-distancing restrictions. Journal of economics \& management strategy 29(4):727-740

Fetzer T, et al (2020) Subsidizing the Spread of Covid19: Evidence from the UK's Eat-out To-help-out Scheme. University of Warwick, Department of Economics

Fisher KA, Tenforde MW, Feldstein LR, Lindsell CJ, Shapiro NI, Files DC, Gibbs KW, Erickson HL, Prekker ME, Steingrub JS, et al (2020) Community and close contact exposures associated with covid-19 among symptomatic adults, 18 years in 11 outpatient health care facilities united states, july 2020. Morbidity and Mortality Weekly Report 69(36):1258

Goolsbee A, Syverson C (2021) Fear, lockdown, and diversion: Comparing drivers of pandemic economic decline 2020. Journal of public economics 193:104,311

Hale T, Angrist N, Goldszmidt R, Kira B, Petherick A, Phillips T, Webster S, CameronBlake E, Hallas L, Majumdar S, et al (2021) A global panel database of pandemic policies (oxford covid-19 government response tracker). Nature Human Behaviour $5(4): 529-538$

Halloran ME, Struchiner CJ (1995) Causal inference in infectious diseases. Epidemiology pp 142-151

Haug N, Geyrhofer L, Londei A, Dervic E, Desvars-Larrive A, Loreto V, Pinior B, Thurner S, Klimek P (2020) Ranking the effectiveness of worldwide covid-19 government interventions. Nature human behaviour 4(12):1303-1312

Hosono K (2021) Epidemic and economic consequences of voluntary and request-based lockdowns in japan. Journal of the Japanese and International Economies p 101147

Howard J, Huang A, Li Z, Tufekci Z, Zdimal V, van der Westhuizen HM, von Delft A, Price A, Fridman L, Tang LH, Tang V, Watson GL, Bax CE, Shaikh R, Questier F, Hernandez D, Chu LF, Ramirez CM, Rimoin AW (2021) An evidence review of face masks against covid-19. Proceedings of the National Academy of Sciences 118(4), DOI 10.1073/pnas.2014564118, URL https://www.pnas.org/content/118/4/ e2014564118, https://www.pnas.org/content/118/4/e2014564118.full.pdf 
medRxiv preprint doi: https://doi.org/10.1101/2021.08.07.21261741; this version posted August 8, 2021. The copyright holder for this preprint (which was not certified by peer review) is the author/funder, who has granted medRxiv a license to display the preprint in perpetuity.

Jarvis CI, Gimma A, van Zandvoort K, Wong KL, Edmunds WJ (2021) The impact of local and national restrictions in response to covid-19 on social contacts in england: a longitudinal natural experiment. BMC medicine 19(1):1-12

Kissler SM, Kishore N, Prabhu M, Goffman D, Beilin Y, Landau R, Gyamfi-Bannerman C, Bateman BT, Snyder J, Razavi AS, et al (2020) Reductions in commuting mobility correlate with geographic differences in sars-cov-2 prevalence in new york city. Nature communications 11(1):1-6

Kong E, Prinz D (2020) Disentangling policy effects using proxy data: Which shutdown policies affected unemployment during the covid-19 pandemic? Journal of Public Economics 189:104,257

Kwon S, Joshi AD, Lo CH, Drew DA, Nguyen LH, Guo CG, Ma W, Mehta RS, Shebl FM, Warner ET, et al (2021) Association of social distancing and face mask use with risk of covid-19. Nature Communications 12(1):1-10

Lai S, Ruktanonchai NW, Zhou L, Prosper O, Luo W, Floyd JR, Wesolowski A, Santillana M, Zhang C, Du X, et al (2020) Effect of non-pharmaceutical interventions to contain covid-19 in china. nature 585(7825):410-413

Lu JG, Jin P, English AS (2021) Collectivismcoco predicts mask use during covid19. Proceedings of the National Academy of Sciences 118(23), DOI 10.1073/ pnas.2021793118, URL https://www.pnas.org/content/118/23/e2021793118, https://www.pnas.org/content/118/23/e2021793118.full.pdf

Madeira A, Palrão T, Mendes AS (2021) The impact of pandemic crisis on the restaurant business. Sustainability 13(1):40

Makhni S, Umscheid CA, Soo J, Chu V, Bartlett A, Landon E, Marrs R (2021) Hand Hygiene Compliance Rate During the COVID-19 Pandemic. JAMA Internal Medicine DOI 10.1001/jamainternmed.2021.1429, URL https://doi.org/10.1001/jamainternmed.2021.1429, https: //jamanetwork.com/journals/jamainternalmedicine/articlepdf/2779293/ jamainternal_makhni_2021_ld_210014_1618936146.0919.pdf

Menni C, Valdes AM, Freidin MB, Sudre CH, Nguyen LH, Drew DA, Ganesh S, Varsavsky T, Cardoso MJ, Moustafa JSES, et al (2020) Real-time tracking of self-reported symptoms to predict potential covid-19. Nature medicine 26(7):10371040

Miyakawa D, Oikawa K, Ueda K (2021) Firm exit during the covid-19 pandemic: Evidence from japan. Journal of the Japanese and International Economies 59:101,118

Miyawaki A, Tabuchi T, Tomata Y, Tsugawa Y (2021) Association between participation in the government subsidy programme for domestic travel and symptoms indicative of covid-19 infection in japan: cross-sectional study. BMJ open 11(4):e049,069 
medRxiv preprint doi: https://doi.org/10.1101/2021.08.07.21261741; this version posted August 8, 2021. The copyright holder for this preprint (which was not certified by peer review) is the author/funder, who has granted medRxiv a license to display the preprint in perpetuity.

All rights reserved. No reuse allowed without permission.

Nishi A, Dewey G, Endo A, Neman S, Iwamoto SK, Ni MY, Tsugawa Y, Iosifidis G, Smith JD, Young SD (2020) Network interventions for managing the covid19 pandemic and sustaining economy. Proceedings of the National Academy of Sciences 117(48):30,285-30,294

Nomura S, Yoneoka D, Shi S, Tanoue Y, Kawashima T, Eguchi A, Matsuura K, Makiyama K, Ejima K, Taniguchi T, et al (2020) An assessment of self-reported covid-19 related symptoms of 227,898 users of a social networking service in japan: Has the regional risk changed after the declaration of the state of emergency? The Lancet Regional Health-Western Pacific 1:100,011

Persson J, Parie JF, Feuerriegel S (2021) Monitoring the covid-19 epidemic with nationwide telecommunication data. arXiv preprint arXiv:210102521

Post RA, Regis M, Zhan Z, van den Heuvel ER (2021) How did governmental interventions affect the spread of covid-19 in european countries? BMC public health 21(1):1-11

Rubin DB (2005) Causal inference using potential outcomes: Design, modeling, decisions. Journal of the American Statistical Association 100(469):322-331

Sheridan A, Andersen AL, Hansen ET, Johannesen N (2020) Social distancing laws cause only small losses of economic activity during the covid-19 pandemic in scandinavia. Proceedings of the National Academy of Sciences 117(34):20,468-20,473

Sonoda S, Kuramochi J, Matsuyama Y, Miyazaki Y, Fujiwara T (2021) Validity of clinical symptoms score to discriminate patients with covid-19 from common cold out-patients in general practitioner clinics in japan. Journal of clinical medicine 10(4):854

Struyf DJDJTYDCLMSRHLEDDJHSA T, Van den Bruel A (2021) Signs and symptoms to determine if a patient presenting in primary care or hospital outpatient settings has covid-19. Cochrane Database of Systematic Reviews (2), DOI 10.1002/14651858.CD013665.pub2, URL https://doi.org//10.1002/ 14651858. CD013665.pub2

Struyf T, Deeks JJ, Dinnes J, Takwoingi Y, Davenport C, Leeflang MM, Spijker R, Hooft L, Emperador D, Dittrich S, et al (2020) Signs and symptoms to determine if a patient presenting in primary care or hospital outpatient settings has covid-19 disease. Cochrane Database of Systematic Reviews (7)

VanderWeele TJ (2008) Ignorability and stability assumptions in neighborhood effects research. Statistics in medicine 27(11):1934-1943

Watanabe T, Yabu T (2021) Japan's voluntary lockdown. Plos one 16(6):e0252,468 
Witteveen D, Velthorst E (2020) Economic hardship and mental health complaints during covid-19. Proceedings of the National Academy of Sciences 117(44):27,27727,284

Yan Y, Malik AA, Bayham J, Fenichel EP, Couzens C, Omer SB (2021) Measuring voluntary and policy-induced social distancing behavior during the covid-19 pandemic. Proceedings of the National Academy of Sciences 118(16)

Yang Y, Liu H, Chen X (2020) Covid-19 and restaurant demand: early effects of the pandemic and stay-at-home orders. International Journal of Contemporary Hospitality Management

Zaitsu M, Hosokawa Y, Okawa S, Hori A, Kobashi G, Tabuchi T (2021) Use of heated tobacco products may be associated with hypertensive disorders of pregnancy and low birth weight in japan: An analysis of the jacsis study. medRxiv 
medRxiv preprint doi: https://doi.org/10.1101/2021.08.07.21261741; this version posted August 8, 2021. The copyright holder for this preprint (which was not certified by peer review) is the author/funder, who has granted medRxiv a license to display the preprint in perpetuity.

All rights reserved. No reuse allowed without permission.

\section{Supplementary Information Appendix}


medRxiv preprint doi: https://doi.org/10.1101/2021.08.07.21261741; this version posted August 8, 2021. The copyright holder for this preprint (which was not certified by peer review) is the author/funder, who has granted medRxiv a license to display the preprint in perpetuity.

All rights reserved. No reuse allowed without permission.

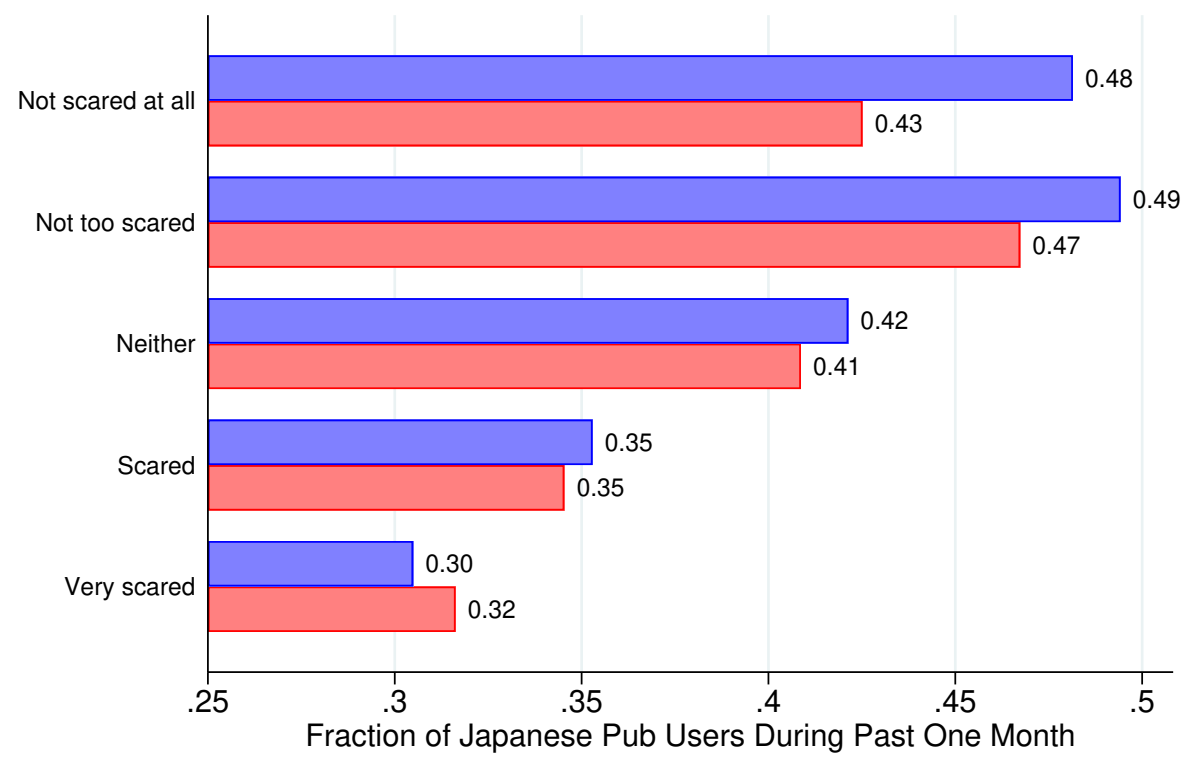

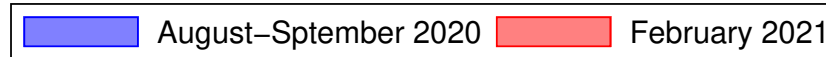

Figure SI1: Utilization Rate of Japanese Pubs and Bars by the Extent of Fear for SARS-CoV-2 
Table SI1: Descriptive Statistics

\begin{tabular}{|c|c|c|c|}
\hline & $\begin{array}{l}\text { Full Sample } \\
\qquad \begin{array}{l}(1) \\
\text { Mean } \\
\text { (S.D.) }\end{array}\end{array}$ & $\begin{array}{c}\text { Prefectures } \\
\text { with the SE } \\
(2) \\
\text { Mean } \\
\text { (S.D.) }\end{array}$ & $\begin{array}{c}\text { Prefectures } \\
\text { without the SE } \\
(3) \\
\text { Mean } \\
\text { (S.D.) }\end{array}$ \\
\hline \multicolumn{4}{|l|}{ Dependent Variables } \\
\hline Utilization of Restaurants and Bars During Past One Month & $\begin{array}{c}0.378 \\
(0.485)\end{array}$ & $\begin{array}{c}0.387 \\
(0.487)\end{array}$ & $\begin{array}{c}0.351 \\
(0.477)\end{array}$ \\
\hline Fever & $\begin{array}{l}0.0184 \\
(0.135)\end{array}$ & $\begin{array}{l}0.0192 \\
(0.137)\end{array}$ & $\begin{array}{l}0.0161 \\
(0.126)\end{array}$ \\
\hline Sore Throat & $\begin{array}{c}0.114 \\
(0.317)\end{array}$ & $\begin{array}{c}0.114 \\
(0.318)\end{array}$ & $\begin{array}{c}0.112 \\
(0.316)\end{array}$ \\
\hline Cough & $\begin{array}{c}0.131 \\
(0.337)\end{array}$ & $\begin{array}{c}0.129 \\
(0.335)\end{array}$ & $\begin{array}{c}0.136 \\
(0.343)\end{array}$ \\
\hline Headache & $\begin{array}{l}0.0187 \\
(0.135)\end{array}$ & $\begin{array}{l}0.0198 \\
(0.139)\end{array}$ & $\begin{array}{l}0.0155 \\
(0.123)\end{array}$ \\
\hline Smell and Taste Disorder & $\begin{array}{l}0.0122 \\
(0.110)\end{array}$ & $\begin{array}{l}0.0125 \\
(0.111)\end{array}$ & $\begin{array}{l}0.0114 \\
(0.106)\end{array}$ \\
\hline \multicolumn{4}{|l|}{ Individual Characteristics } \\
\hline Age & $\begin{array}{c}50.53 \\
(16.510)\end{array}$ & $\begin{array}{c}49.92 \\
(16.600)\end{array}$ & $\begin{array}{c}52.34 \\
(16.100)\end{array}$ \\
\hline College Graduate & $\begin{array}{c}0.512 \\
(0.500)\end{array}$ & $\begin{array}{c}0.531 \\
(0.499)\end{array}$ & $\begin{array}{c}0.455 \\
(0.498)\end{array}$ \\
\hline Married & $\begin{array}{c}0.629 \\
(0.483)\end{array}$ & $\begin{array}{c}0.615 \\
(0.487)\end{array}$ & $\begin{array}{c}0.67 \\
(0.470)\end{array}$ \\
\hline Worker & $\begin{array}{c}0.642 \\
(0.480)\end{array}$ & $\begin{array}{c}0.648 \\
(0.478)\end{array}$ & $\begin{array}{c}0.622 \\
(0.485)\end{array}$ \\
\hline Household with Income More Than JPY 7 Million & $\begin{array}{c}0.325 \\
(0.468)\end{array}$ & $\begin{array}{c}0.338 \\
(0.473)\end{array}$ & $\begin{array}{c}0.285 \\
(0.452)\end{array}$ \\
\hline Smoker & $\begin{array}{c}0.21 \\
(0.407)\end{array}$ & $\begin{array}{c}0.212 \\
(0.408)\end{array}$ & $\begin{array}{c}0.205 \\
(0.403)\end{array}$ \\
\hline $\begin{array}{l}\text { Used Japanese Pubs and Bars During the Period Before the Pandemic } \\
\text { ("Japanese Pub Users") }\end{array}$ & $\begin{array}{l}0.456 \\
(0.498)\end{array}$ & $\begin{array}{l}0.474 \\
(0.499)\end{array}$ & $\begin{array}{c}0.401 \\
(0.490)\end{array}$ \\
\hline Not Scared at SARS-CoV-2 & $\begin{array}{l}0.373 \\
(0.484)\end{array}$ & $\begin{array}{l}0.379 \\
(0.485)\end{array}$ & $\begin{array}{l}0.356 \\
(0.479)\end{array}$ \\
\hline Observations & 25,338 & 19,007 & 6,331 \\
\hline
\end{tabular}

Notes: The sample consists of persons who lived within $50 \mathrm{Km}$ from the border which separates the prefectures with and without the SE (state of emergency) declaration. 


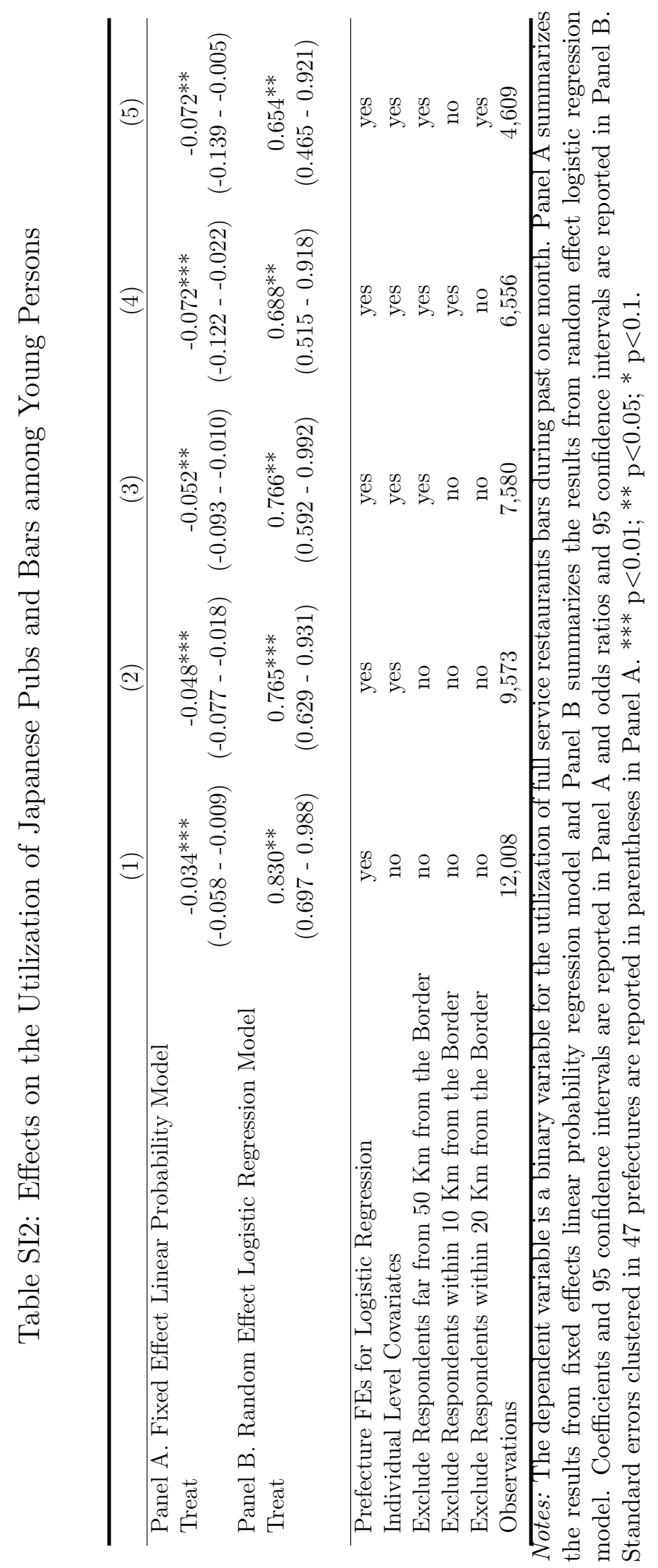




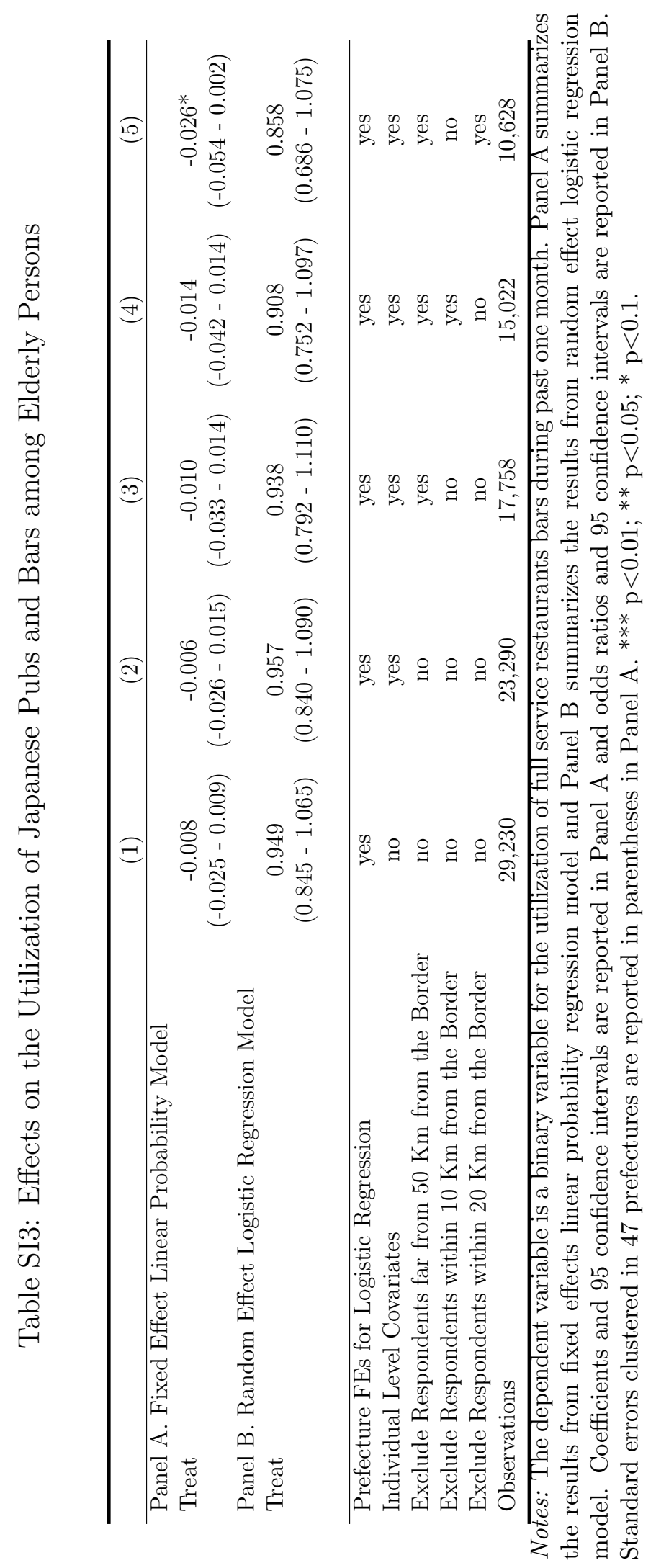




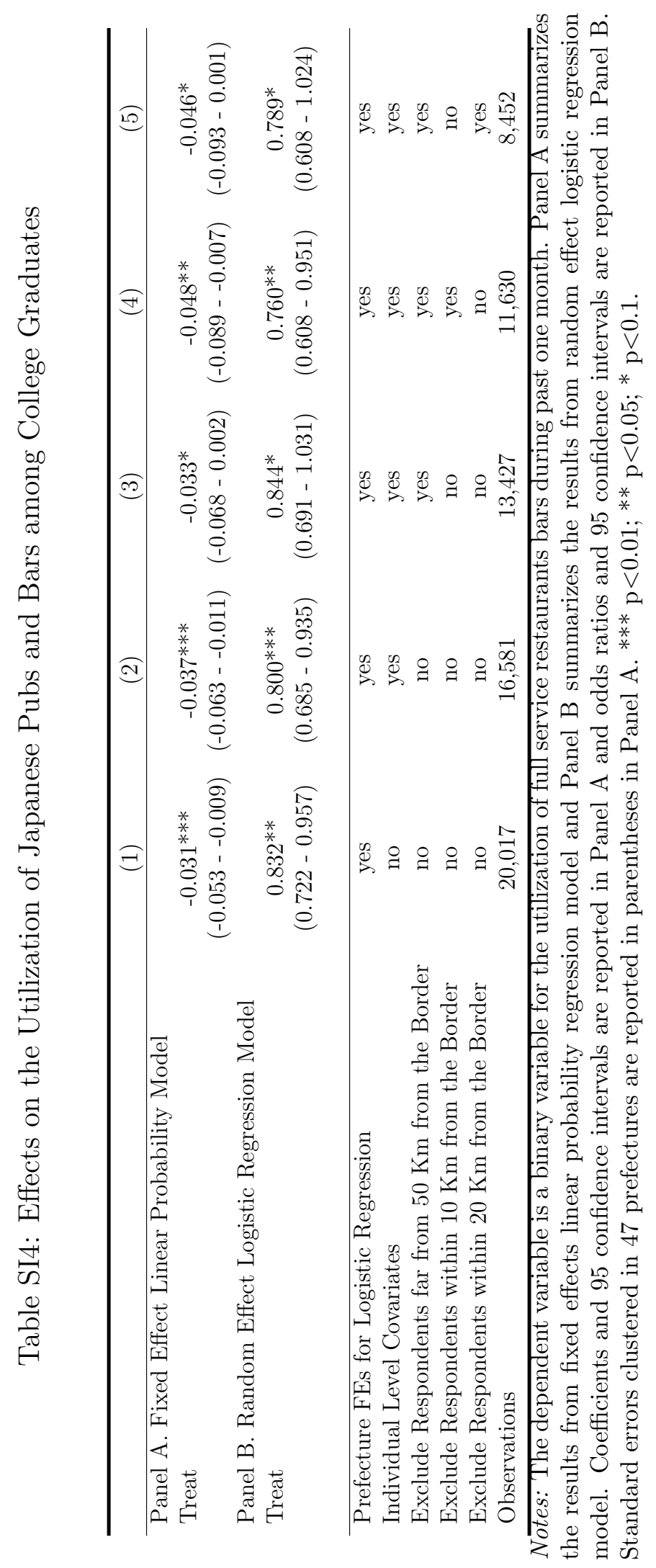




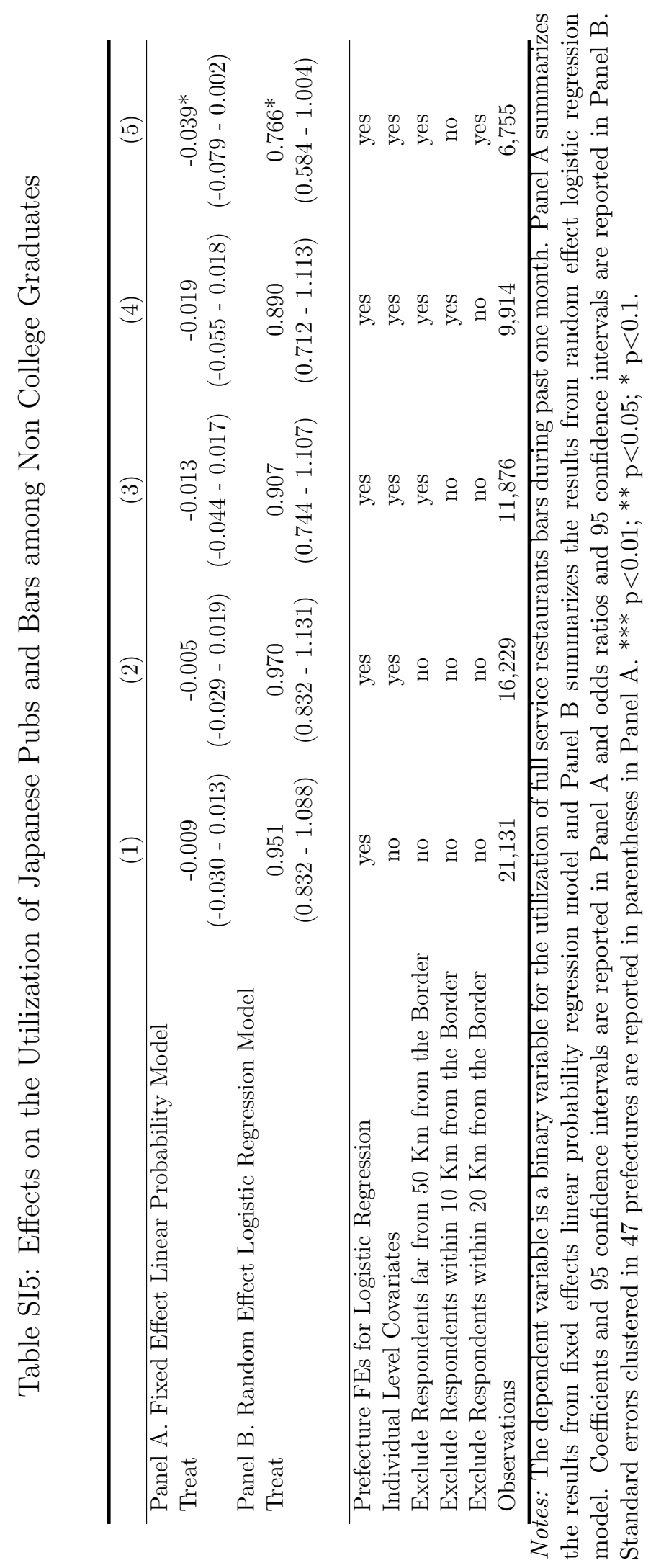




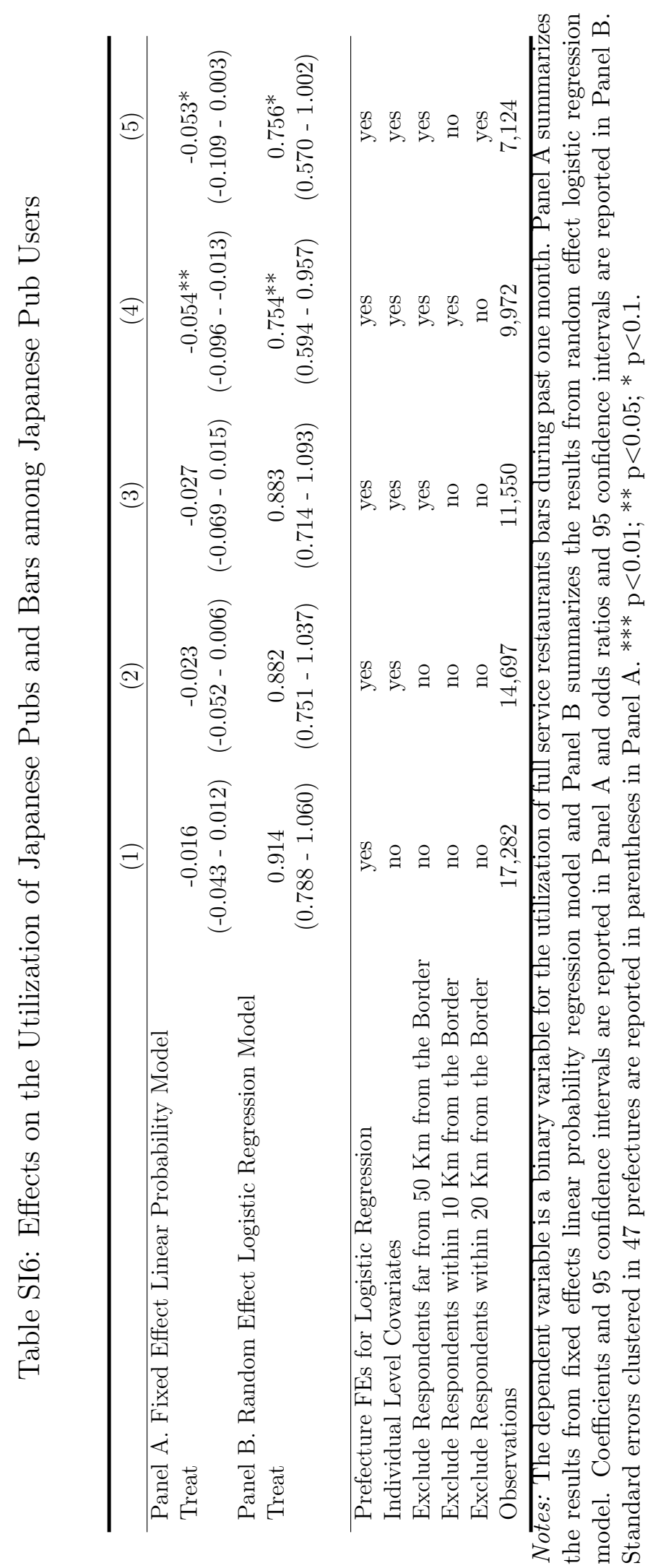




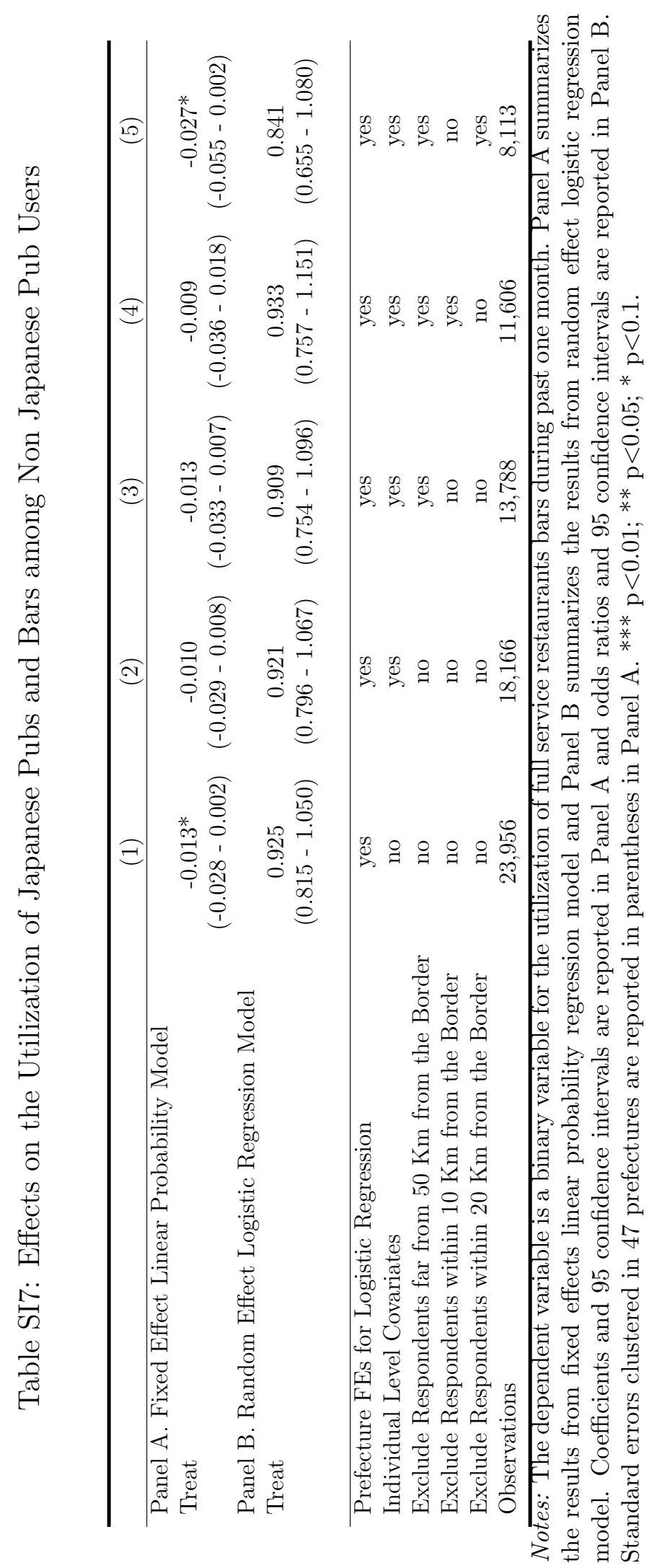




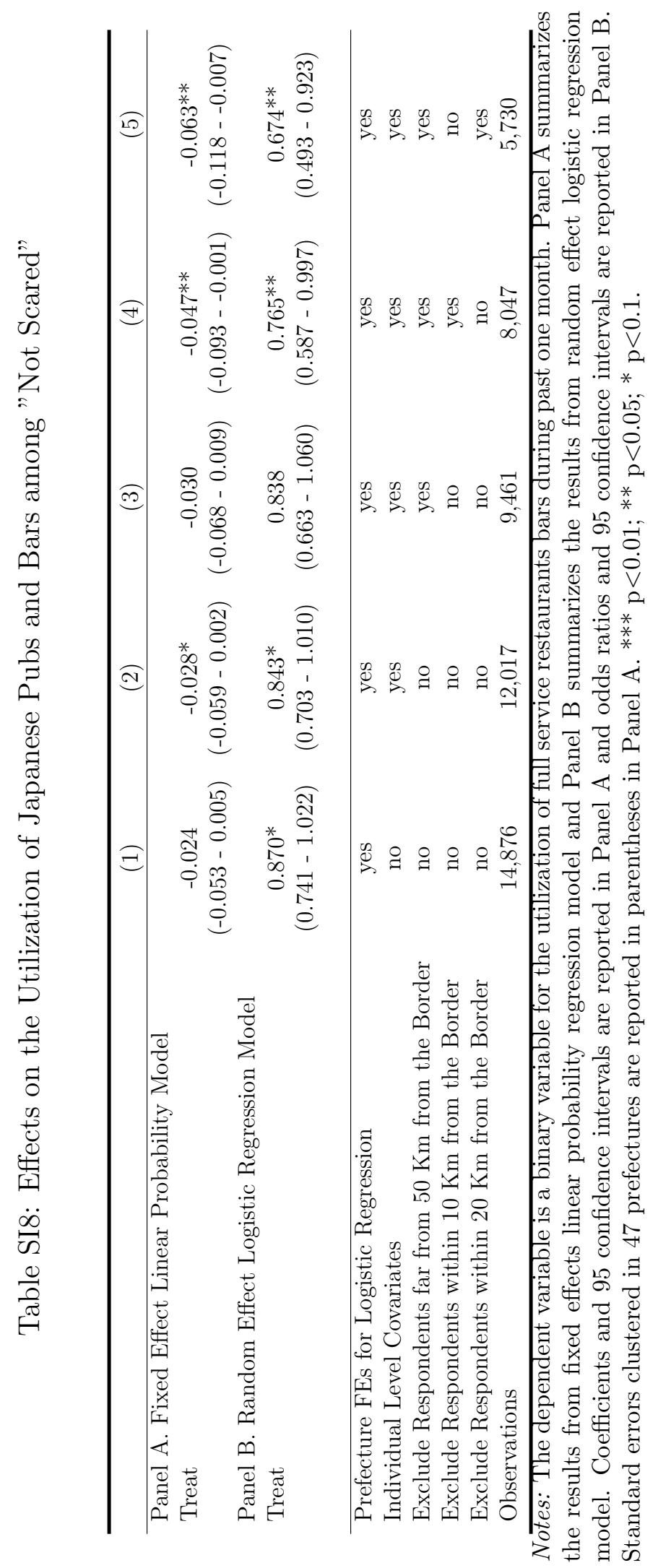




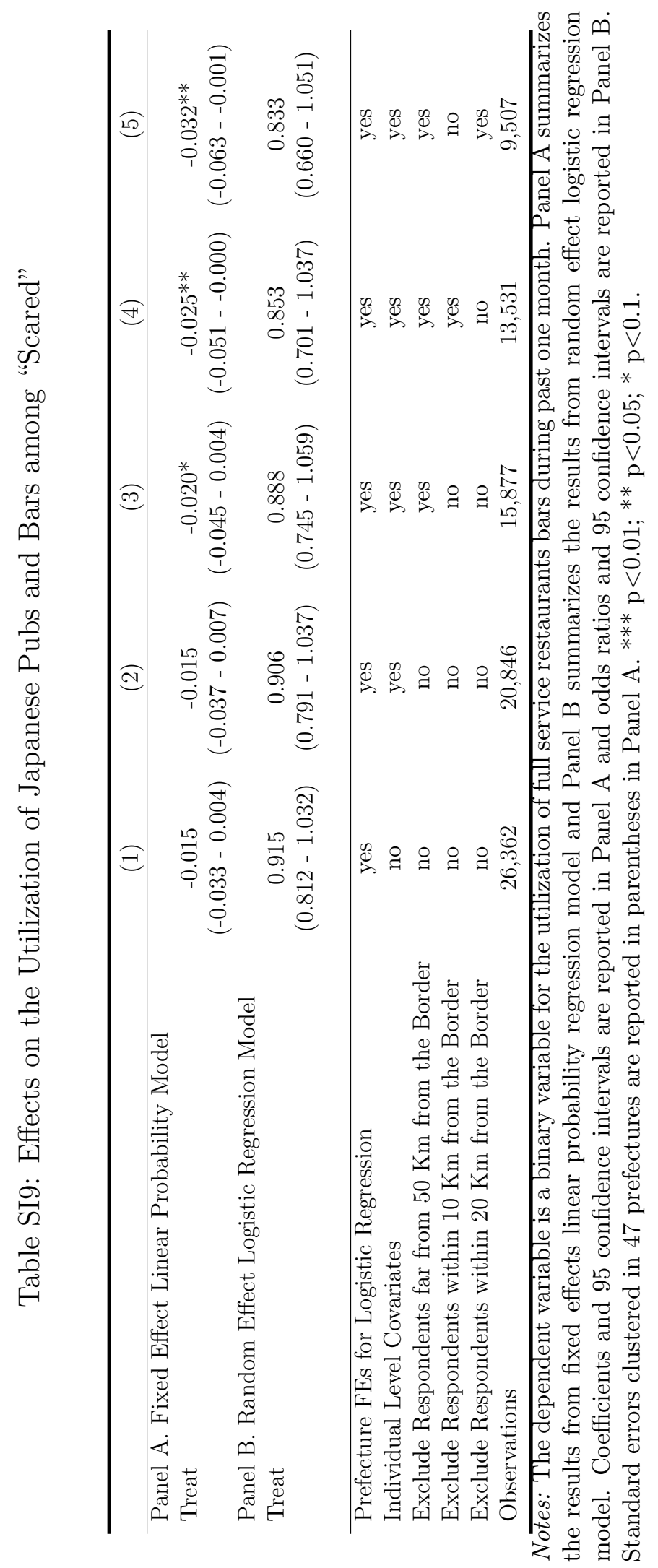




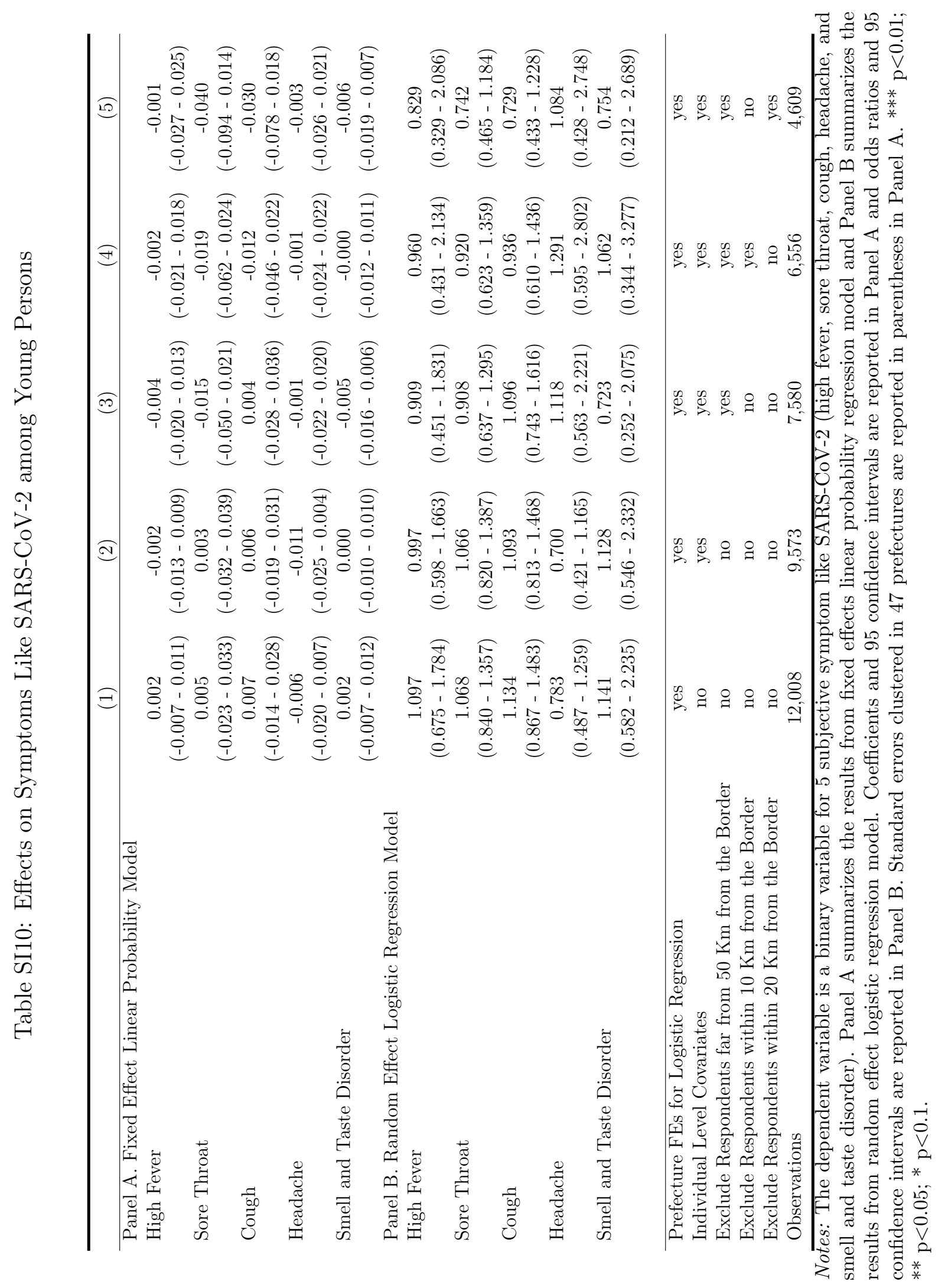




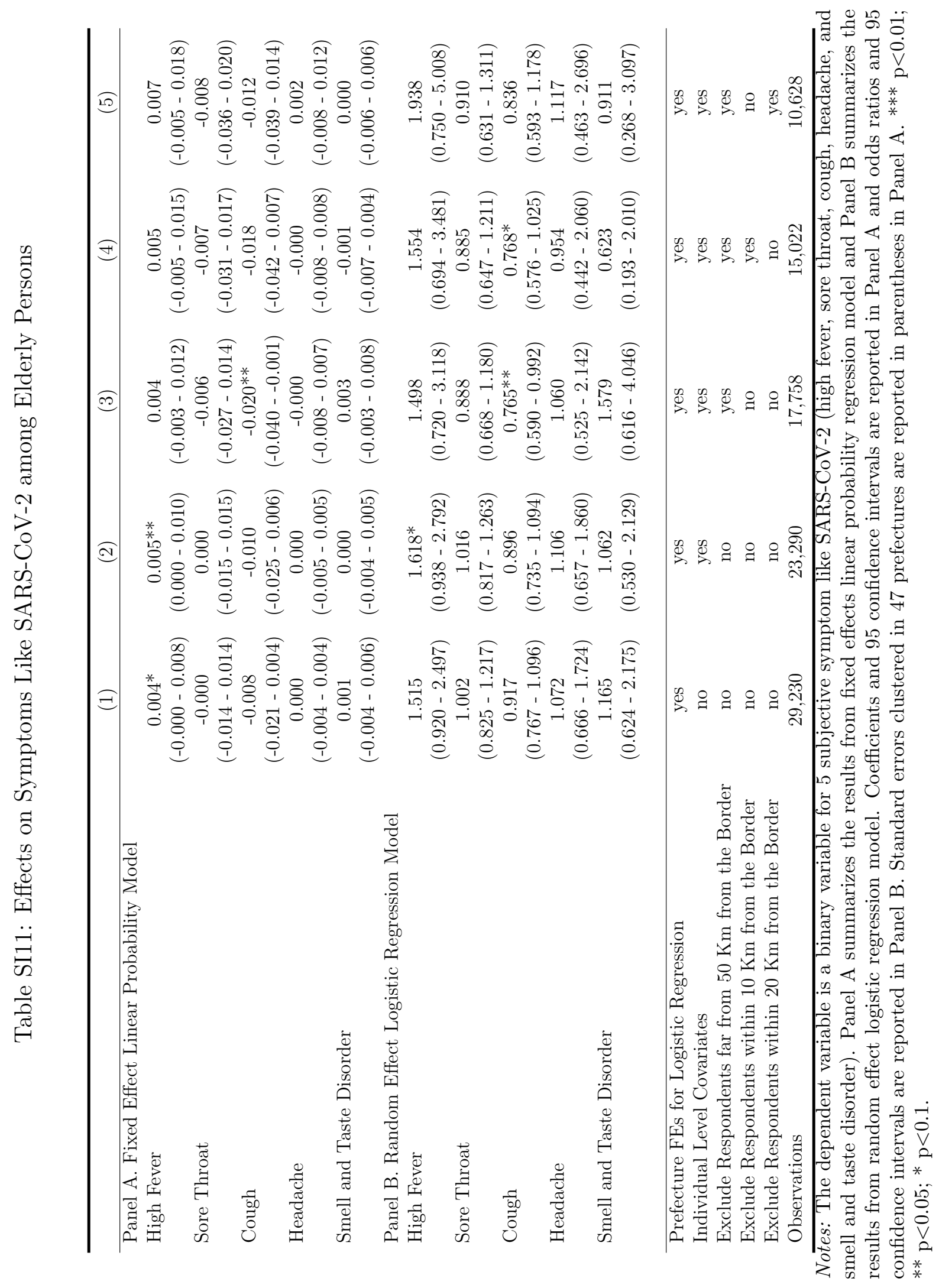




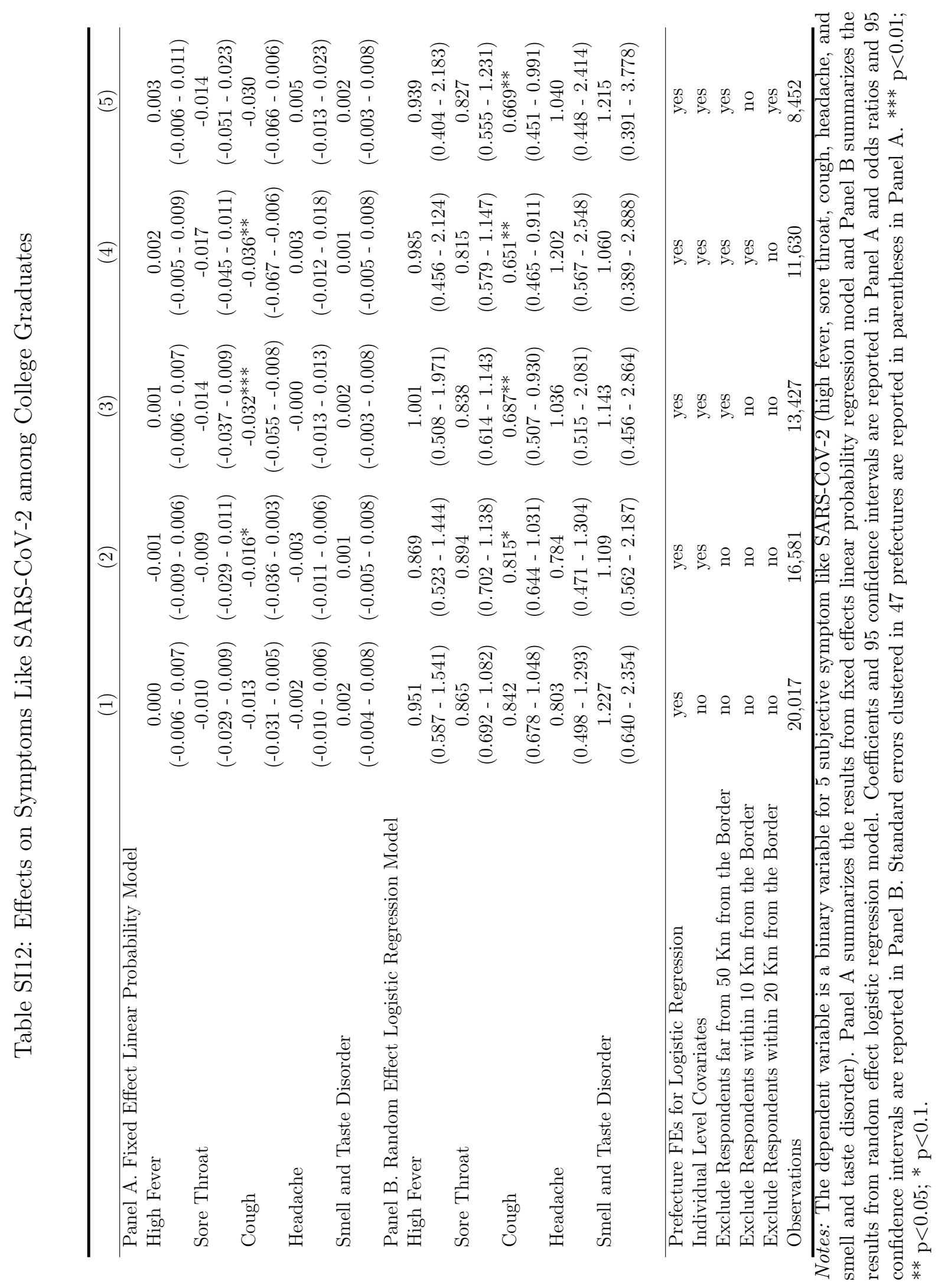




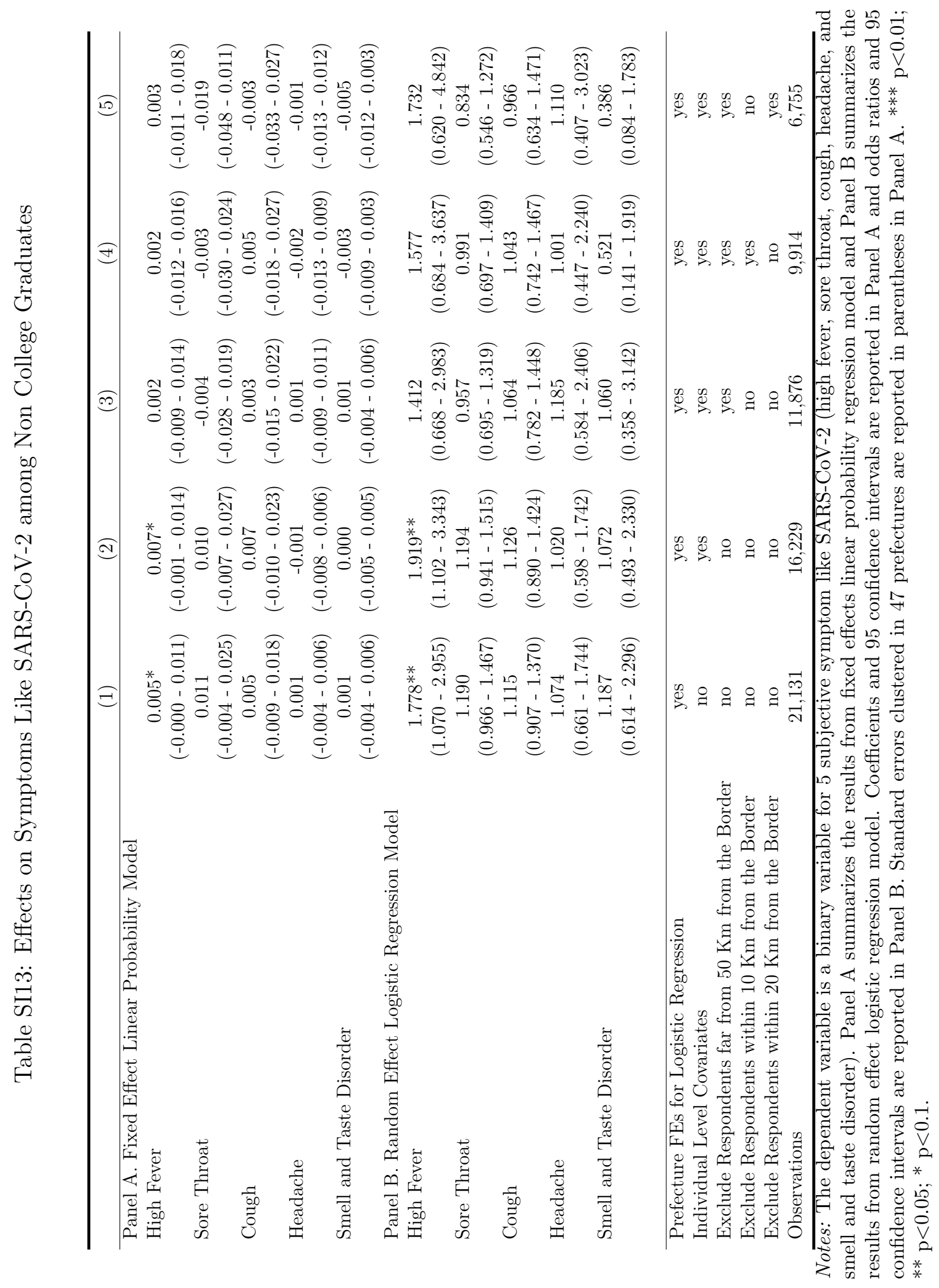




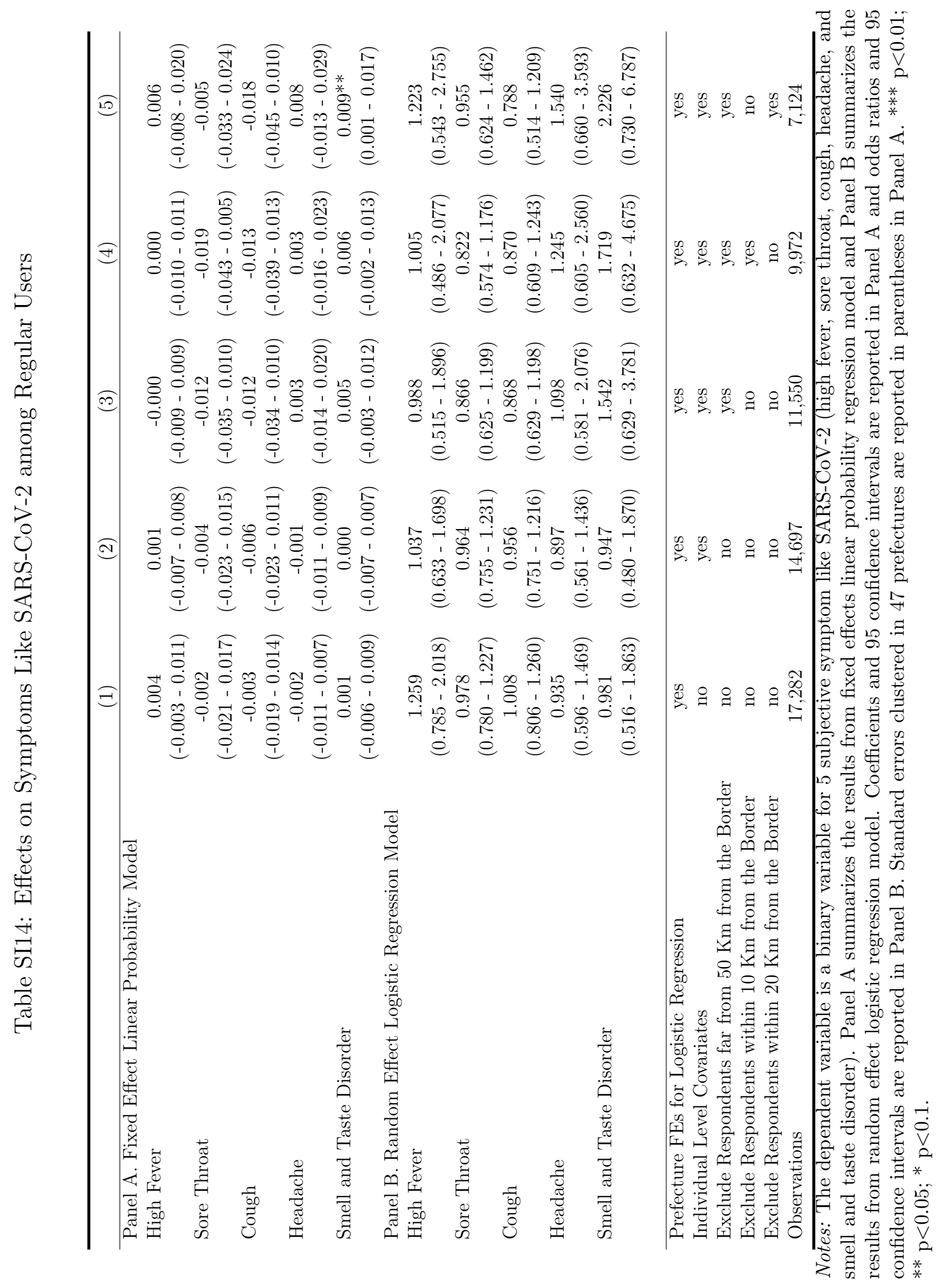




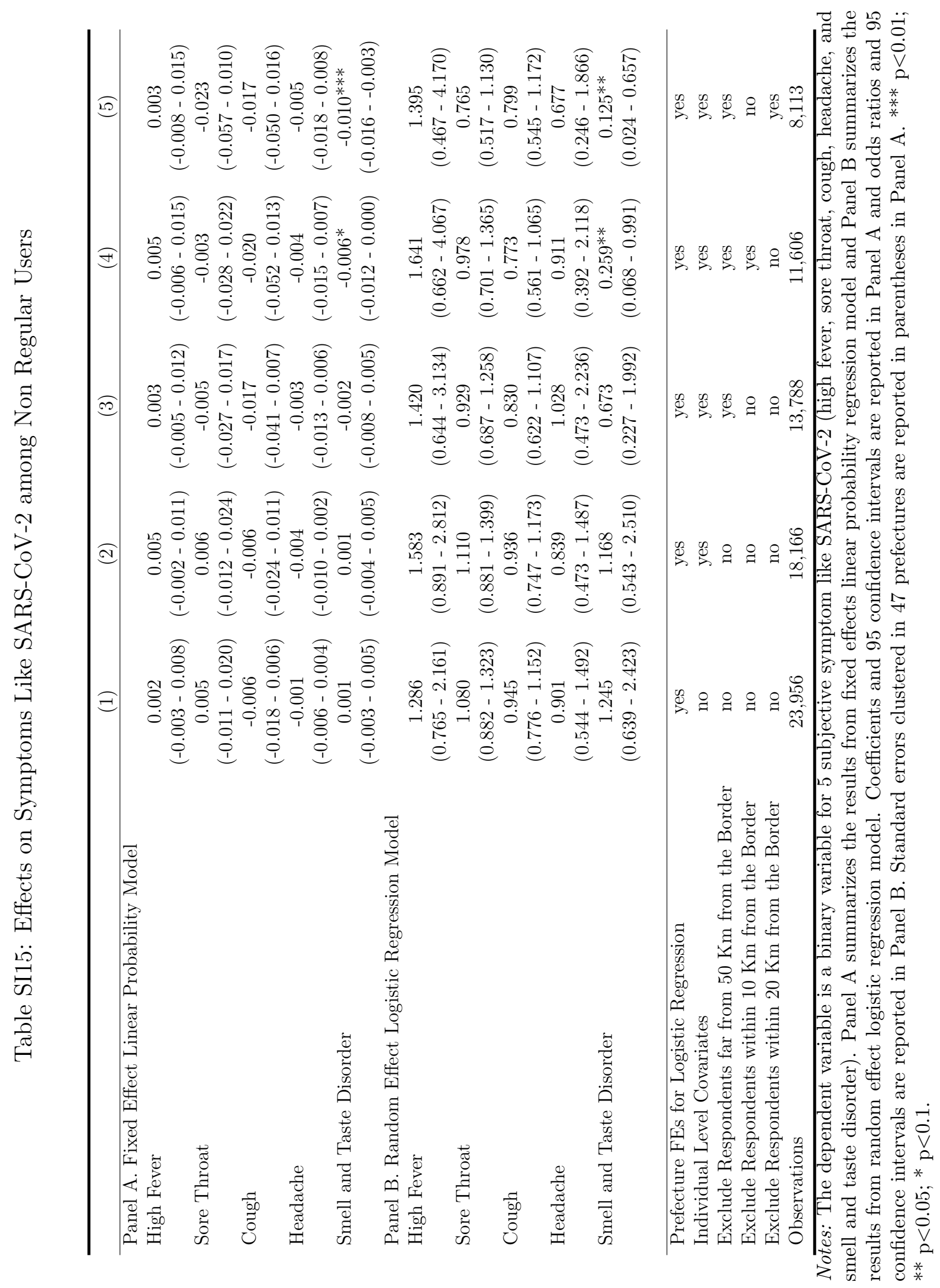




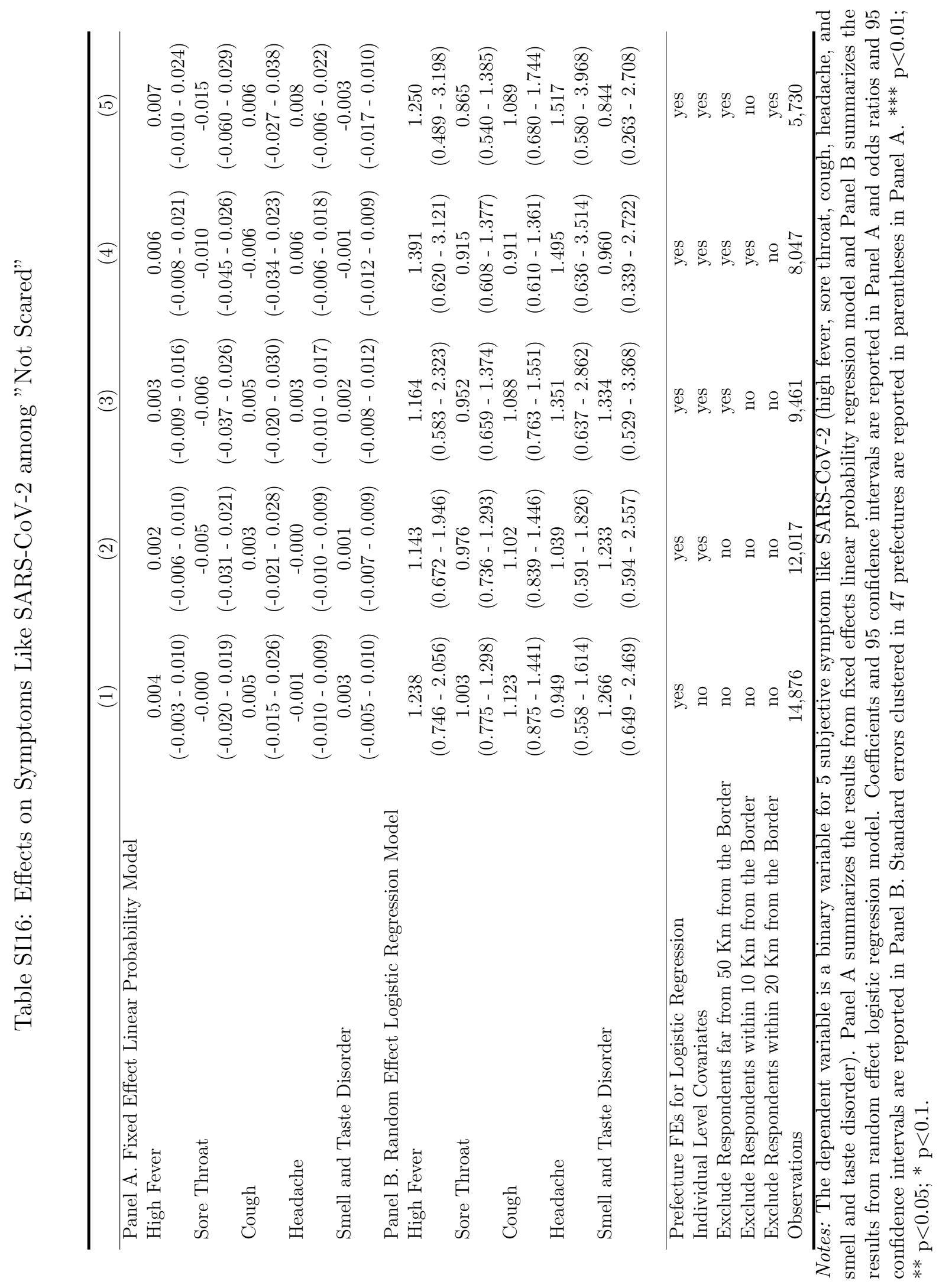




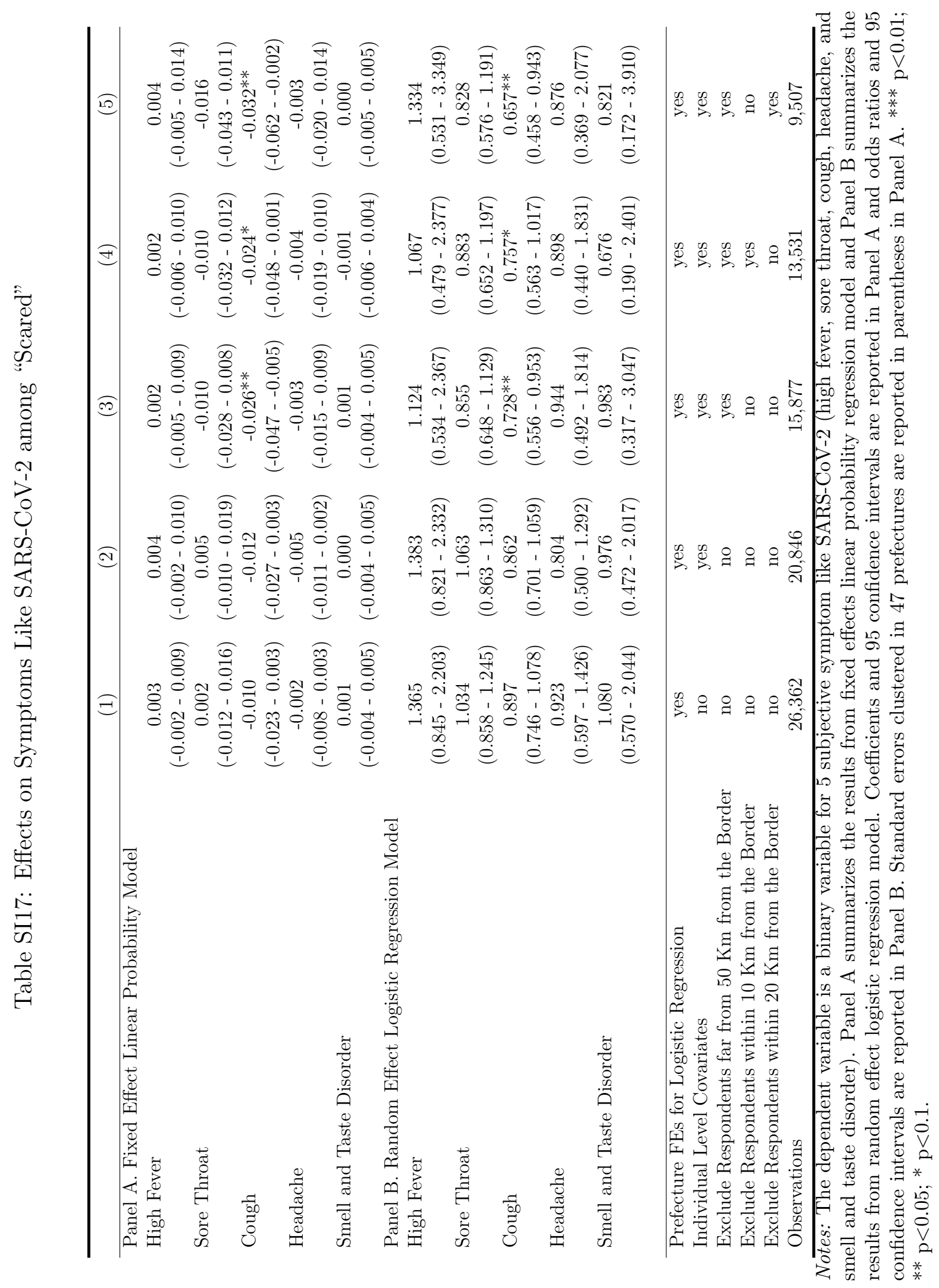



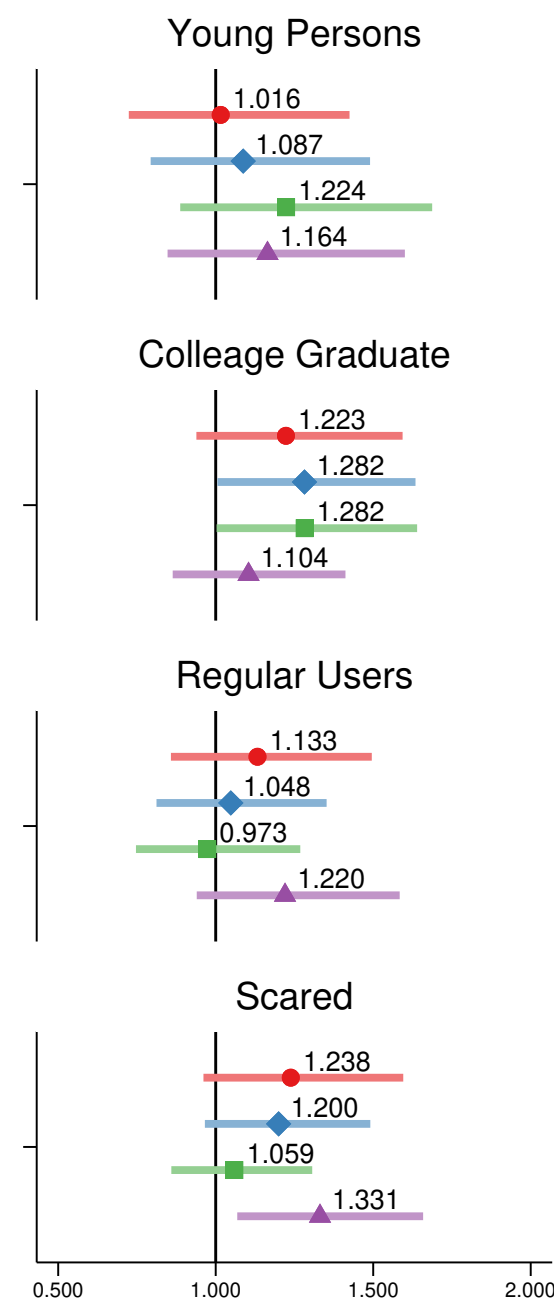

Odds Ratio \& $95 \%$ Cls
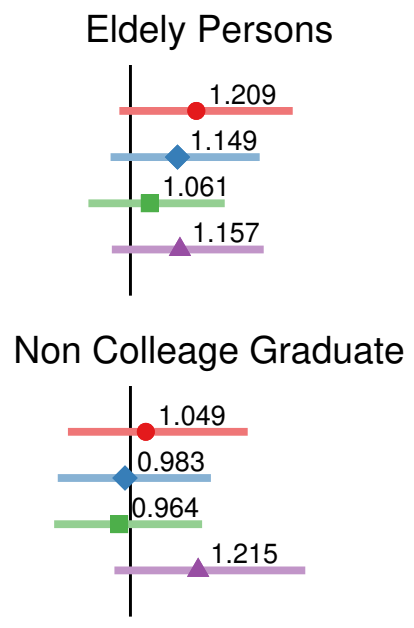

Non Regular Users

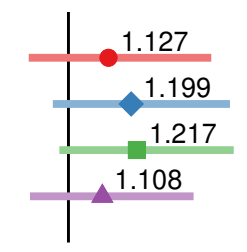

Not Scared

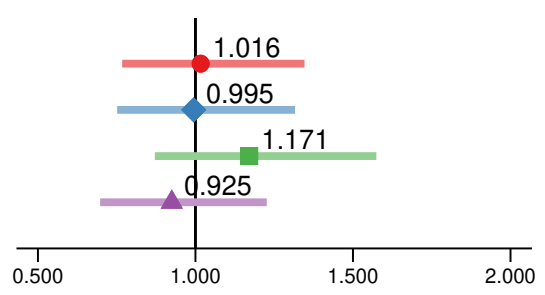

.000

\section{- Not Go to Travel $\quad$ Avoid Outings \\ Take a Social Distance $\Delta$ Avoid Crowds}

Figure SI2: Effects on Going Out Behaviors.

Note: "Young persons" represents the individuals aged 40 years old or less. "Regular Users" represents the individuals who used Japanese pubs and bars before the pandemic. "Scared" and "Not scared" represent the individuals who reported that they were scared (not scared) at SARS-CoV-2 in the first wave. 